\title{
When Can School Inputs Improve Test Scores?
}

\author{
Jishnu Das, Stefan Dercon, \\ James Habyarimana and Pramila Krishnan
}

July 2004

CWPE 0437

Not to be quoted without permission 


\title{
When Can School Inputs Improve Test Scores?
}

\author{
Jishnu Das (Development Research Group, World Bank) \\ Stefan Dercon (Oxford University) \\ James Habyarimana (Harvard University) \\ Pramila Krishnan (Cambridge University)*
}

March 16, 2004

\begin{abstract}
Most studies fail to find an impact of school inputs on outcomes such as test scores. We argue that this might be a consequence of ignoring the possibility that households respond optimally to changes in school inputs and thus obscure the real effect of such provision on cognitive achievement. To incorporate the forward-looking behavior of households, we present a household optimization model relating household resources and cognitive achievement to school inputs. In this framework if household and school inputs are technical substitutes in the production function for cognitive achievement, the impact of unanticipated inputs is larger than that of anticipated inputs. We test the predictions of the model for non-salary cash grants to schools using a unique data set from Zambia. We find that household educational expenditures and school cash grants are substitutes with a coefficient of elasticity between -0.35 and -0.52 . Consistent with the optimization model, anticipated funds have no impact on cognitive achievement, but unanticipated funds lead to significant improvements in learning. We are thus able both to order the effects of different kinds of spending and capture their impact on cognitive achievement.
\end{abstract}

\footnotetext{
${ }^{*}$ Corresponding Author: Jishnu Das (jdas1@worldbank.org). We thank Hanan Jacoby and workshop participants at the World Bank and NEUDC (Yale) for comments. Funding for the survey was provided by the Department for International Development (UK). The findings, interpretations, and conclusions expressed in this paper are those of the authors and do not necessarily represent the views of the World Bank, its Executive Directors, or the governments they represent. Working papers describe research in progress by the authors and are published to elicit comments and to further debate.
} 


\section{Introduction}

In the last two decades the relationship between schooling inputs and educational outcomes has received considerable attention. Although it is recognized that households play a critical role in the determination of such outcomes, the literature has split in two strands. ${ }^{1}$ One strand, concerned with the impact of school inputs on cognitive achievement, has focused on estimating educational production functions where cognitive achievement is determined as a function of schooling inputs. The second strand is concerned with the effect of household characteristics on cognitive achievement independent of school inputs. However, the notion that household responses themselves affect the relationship between cognitive achievement and school inputs has received little attention in the literature.

In a recent paper Todd and Wolpin (2003) point out that in the presence of household responses, estimates based on the production function approach will capture a "policy-effect" that incorporates both the marginal impact of school inputs on outcomes as well as household responses to such inputs. This is the question addressed here: How are we to isolate and understand the relationship between school inputs and cognitive achievement in an environment where households respond to the provision of such inputs?

To examine this question we first derive a household optimization model of cognitive achievement. The model incorporates the basic assumption that households respond optimally to the provision of inputs at the school level. However, we also incorporate the notion that households are forward-looking so that responses occur not only in the period that school inputs are provided, but the moment that new information becomes available. Our explicit consideration of the dynamics has the strong implication that since household adjustments occur with any new information, production function parameters can be identified only through the impact of unanticipated inputs on cognitive achievement.

In this framework, the impact of school inputs depends on (a) whether they are anticipated or not and (b) the extent of substitutability between household and school inputs in the production function for cognitive achievement. If household and school inputs are technical substitutes, an anticipated increase in inputs in the next period increases household contributions in the current period and decreases them in the next, whereas if they are technical complements, the impact of anticipated increases in school inputs on current contributions depends on the strength of the households' preferences for a smooth consumption path. Unanticipated increases in school inputs

\footnotetext{
${ }^{1}$ The path-breaking Coleman Report (1966) for instance stresses the importance of household characteristics for child achievement.
} 
in the next period preclude household responses in either the current period or the next. These differences lead to a testable prediction: If household and school inputs are (technical) substitutes, unanticipated inputs will have a larger impact on cognitive achievement than anticipated inputs; if they are complements, the relative effects depend on household preferences.

We test this prediction using data for Zambia in 2002-2003. The educational environment in the country is particularly well suited for our empirical exercise. The system is largely based on public schools (less than 2 percent of all schools are privately run) and the country has a history of high enrollment rates and school participation, suggesting that household involvement in children's education is high. ${ }^{2}$ In 2000 the government legislated a fixed cash grant to every school. These grants were large. Among rural schools, they represented 66 percent of household level educational expenditures for the lowest wealth deciles and 19 percent for the top wealth decile. Moreover the simplicity of the allocation rule ensured that the grants reached their intended recipients (see Das, Dercon, Habyarimana, and Krishnan 2003), suggesting that in the year of the survey the fixed cash grants would be anticipated by households making their educational investment decisions for the year.

In addition schools could also receive cash from other sources, but these alternative sources were highly unreliable and unpredictable. In the year of the survey, less than 25 percent of all schools received such grants and conditional on receipt, there was tremendous variation with some schools receiving 30 times as much as others. Apart from cash, few resources were distributed to schools during the year of the survey. Finally, following an agenda of "free" education, all institutionalized parental contributions to schools were banned in April 2001 (typically these took the form of Parent Teacher Association fees). Taken together this implied that educational expenditures for children could be met either through cash grants to schools or through direct parental contribution at the level of the household. These two factors present exactly the framework required to test our model with high parental contributions towards educational inputs on the one hand and two different streams of cash disbursements to schools, one steady and the other unpredictable, on the other.

To exploit the characteristics of the educational environment, we collected a unique data set for a representative sample of schools in four provinces of the country (covering 58 percent of the population). The survey includes data on school inputs as well as two test scores on the same sample of students one year apart. To supplement this data, we also collected information for households matched to a sub-sample of schools identified as "remote" using GIS mapping tools. This allows us to directly relate household and school inputs in an environment where issues of

\footnotetext{
${ }^{2}$ Net enrollments are upwards of 80 percent for both boys and girls (Figures 2a and 2b).
} 
school choice are eliminated. We are then interested in the effect of anticipated and unanticipated cash grants to schools on household educational expenditures and cognitive achievement.

We find strong support for the household approach to cognitive achievement. Using the matched school-household data, our results suggest that household educational expenditures and cash grants to schools are substitutes. The elasticity of substitution between the two is high and significant, with estimates ranging from -0.35 to -0.52 depending on the specification used. In line with the predictions of our model, unanticipated grants have a significant and substantial impact on the growth of cognitive achievement while the effect of anticipated grants is small and insignificant. These results hold for the subjects of Mathematics and English (although the difference is more pronounced for the latter), and are robust to potential mis-specification arising from omitted variables in the regression.

The significance of our results goes beyond the particular policy environment considered here. A failure to reject the null hypothesis in studies that use the production function approach could arise either because the effect of school inputs on cognitive achievement through the production function is zero or because households substitute their own resources for such inputs. While in our case the substitution may take the form of textbooks or writing materials, in a more general setting it may include parental time, private tuition and other inputs. The results show that the policy effect of school inputs is different from the production function parameters. This has vital consequences both for estimation techniques and for educational policy; a detailed discussion comes later.

This work is innovative for a number of reasons. First, the methodology adopted here extends the work of Becker and Tomes (1986) to the determination of cognitive achievement and thus allows household responses and school inputs to be incorporated in a single conceptual framework. Second, the unique data collected on matched schools and households permits the direct estimation of household responses to school inputs; while this is clearly an important issue for policy, there are few direct estimates of this relationship. Third, the combination of funding patterns in the country and panel data on cognitive achievement provides an excellent opportunity to separate policy effects and production function parameters of schooling inputs; doing so yields new insights on the process through which school inputs may affect educational outcomes. The methodology and the unique data thus provide a firm microeconomic foundation for the relationship between school inputs and cognitive achievement in the context of a household optimization model.

The remainder of the paper is structured as follows. Section 2 reviews the literature. Section 3 presents the model and the empirical specification is derived in Section 4. Section 5 describes the 
data and sampling technique and Section 6 presents the results from the matched school-household data. Section 7 presents the results of anticipated and unanticipated cash grants on the growth of cognitive achievement while Section 8 discusses the policy relevance of our work and possibilities for future research.

\section{Review of the Literature}

This work relates to three strands of the literature. The first examines the relationship between schooling inputs and cognitive achievement in the context of production functions. The second examines the impact of household characteristics on educational outcomes. Finally, a third strand studies the impact of public subsidies on private outcomes, mostly in the context of labor supply and private transfers. We describe each of these briefly.

\subsection{Production Function}

The literature on educational production functions (for a review, see Hanushek 1997) attempts to estimate the effect of school inputs on cognitive achievement. The estimation concern that most studies have dealt with is the presence of unobserved heterogeneity, which could contaminate estimates if correlated with the provision of inputs. In response to the omitted variable problem that such heterogeneity creates, studies have tried to exploit "natural-experiments" (Angrist and Lavy 1999; Case and Deaton 1999; Urquiola 2003), "value-added" specifications (Hanushek 1971) or more recently, randomized treatment-control designs (Banerjee, Cole, Duflo, and Linden 2003; Glewwe 2002 provides a review) to argue for causality. Below, we show that our approach allows for greater flexibility in the treatment of unobserved heterogeneity-heuristically, since such heterogeneity is already known at time period $t-1$, it has no effect on growth rates between $t-1$ and $t .^{3}$

\subsection{Household Characteristics}

At the level of the household, studies have examined the relationship between educational outcomes such as enrollment and drop-outs and household characteristics in the context of a household optimization model (Glewwe 2002 and Jacoby and Skoufias 1997). ${ }^{4}$ Fewer studies have examined the role of household characteristics on cognitive achievement; exceptions include Brown (2003), Case and Deaton (1999) and Glewwe and Jacoby (1994) who look at the relationship between parental education and child learning, and Alderman and others (1997) who examine the effect of household income on test scores.

\footnotetext{
${ }^{3}$ This is not without restrictions; for a more detailed comment see Footnote 10.

${ }^{4}$ We also follow a close parallel literature on consumption and health. For instance, optimal growth paths derived in our model are similar to those in Foster (1995) who considers the impact of rice prices on child weight in Bangladesh and Dercon and Krishnan (2000) who relate adult sickness to weight in Ethiopia.
} 
Closer to the question on how optimal responses may alter the relationship between inputs and outcomes is Lazear's (2001) study on class size and achievement. In a theoretical examination of school responses, Lazear (2001) argues that learning in classrooms depends both on the size of the class as well as the number of "disruptive" children allocated to every class. Optimizing behavior on the part of the school then implies that less "disruptive" students are allocated to larger classes and this creates a spurious positive relationship between class size and cognitive achievement. This paper extends the notion of optimal responses to the household, arguing that similar processes will attenuate the relationship between school inputs and achievement.

\subsection{Effect of Government Subsidies}

Our findings on household responses do however have an established precedent in the literature on private responses to public transfer programs. The research on this front has typically examined labor supply responses (Moffitt 1992; Ravallion and Datt 1995) and private transfers (Cox and Jimenez 1995 and Rosenzweig and Wolpin 1994) to find that the effect of government subsidies is generally attenuated through the presence of household responses. The Euler framework developed here has also been used to assess the extent of household responses to school feeding programs. Jacoby (2002) for instance, tests for a "fly-paper" effect in the Philippines by examining the difference in household calorific intake for children on school and non-school days. There is, however, a gap in the literature on household responses to school inputs, partly due to tricky sampling issues (more on this below) and partly due to the predominance of the production function approach in the literature relating schooling inputs to outcomes. By providing estimates on the size of these responses, we thus suggest areas for future research.

\section{Theoretical Framework}

\subsection{The Conceptual Experiment}

Consider a household that receives a single school input, that can either be anticipated or unanticipated. The anticipated input is fully incorporated into the utility maximization problem. For the unanticipated input, households expectations at time $t-1$ (when household decisions are made) are zero, so that they are unable to respond by adjusting their own expenditures. How do these different types of inputs affect cognitive achievement? 


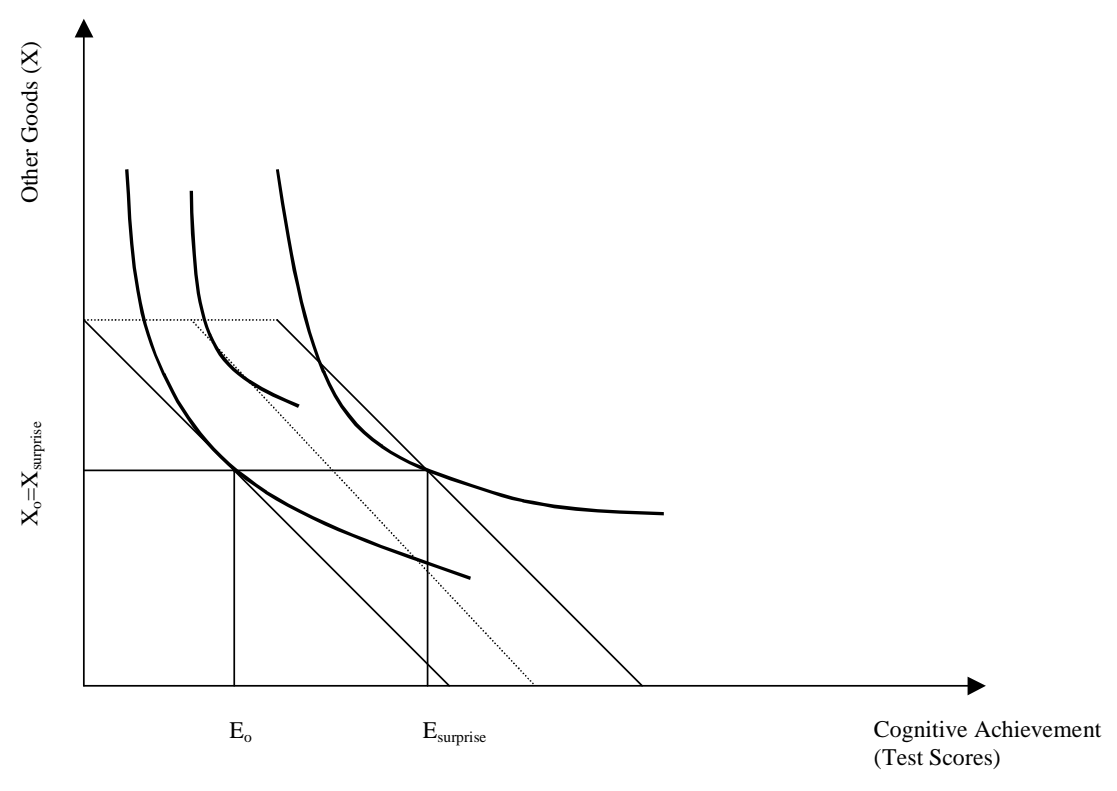

Figure 1. Household Substitution

Figure 1 depicts this conceptual exercise in the case where household preferences are defined over cognitive achievement and other goods. For simplicity, we assume that cognitive achievement is related to schooling inputs through a single-input linear production function. In this framework, any additional unanticipated input will sustain expenditure on all other goods at $X_{0}$. Consequently the change in cognitive achievement will reflect entirely the characteristics of the production function mapping inputs to attainment, moving the household (for instance) from $E_{0}$ to $E_{\text {surprise }}$. Consider now the impact of inputs of the same magnitude that are fully anticipated by the household at time $t-1$. To the extent that this change is viewed as permanent by the household, the budget constraint will shift out to the outer (non-dashed) linear at time $t-1$ itself reflecting the fact that households will optimally incorporate all future information into their decisions at $t-1$. More generally, it could be that the change is (rationally) expected to last a fixed number of years, in which case the budget constraint would shift to an intermediate level (shown by the dashed line) representing the change in permanent income secondary to the anticipated inputs. In either case, there will be no difference in educational inputs provided by the household between $t-1$ and $t$. This difference forms the basis of our statistical test: Cognitive achievement should respond to unanticipated rather than anticipated inputs.

This special case implicitly assumes that household and school inputs are fully substitutable in the production function for cognitive achievement and therefore anticipated changes have no impact between two subsequent time periods. In the formalization of the model below we introduce two new components. First, we view cognitive achievement as a durable good with household preferences defined over it's stock. Second, we incorporate the production function for cognitive achievement 
as a constraint in our optimization. Below we see that this affects the program directly through the user-cost of the durable good. In general, anticipated and unanticipated inputs will have differential effects, but the relative size of these effects will depend on the extent of substitutability between household and school provision of the input.

We start with two general assumptions on preferences and the production function for cognitive achievement. The Euler equation derived defines conditions governing the growth of test scores $^{5}$. Based on this solution we discuss the differential impact of anticipated and unanticipated school inputs on test-score growth. Finally, we consider how credit constraints can affect our results.

\subsection{Model}

A household (with a single child attending school) derives (instantaneous) utility from the cognitive achievement of the child $T S$ and the consumption of other goods $X$. The household maximizes an inter-temporal utility function $U($.$) , additive over time and states of the world with$ discount rate $\beta(<1)$ subject to an inter-temporal budget constraint (IBC) relating assets in the current period to assets in the previous period, current expenditure and current income. Finally, cognitive achievement is determined by a production function relating current achievement $\left(T S_{t}\right)$ to past achievement $\left(T S_{t-1}\right)$, household educational inputs $\left(z_{t}\right)$, school inputs $\left(w_{t}\right)$, non time-varying child characteristics $(\mu)$ and non time-varying school characteristics $(\eta)$. We impose the following structure on preferences and the production function for cognitive achievement:

[A1] Household utility is additively separable, increasing and concave in cognitive achievement and other goods.

[A2] The production function for cognitive achievement is given by $T S_{t}=F\left(T S_{t-1}, w_{t}, z_{t}, \mu, \eta\right)$ where $F($.$) is concave in its arguments.$

Under [A1] and [A2] the household problem is

$$
\begin{aligned}
\operatorname{Max}_{\left(X_{t}, z_{t}\right)} U_{\tau} & =E_{\tau} \sum_{t=\tau}^{T} \beta^{t-\tau}\left[u\left(T S_{t}\right)+v\left(X_{t}\right)\right] \text { s.t. } \\
A_{t+1} & =(1+r) \cdot\left(A_{t}+y_{t}-P_{t} X_{t}-z_{t}\right) \\
T S_{t} & =F\left(T S_{t-1}, w_{t}, z_{t}, \mu, \eta\right) \\
A_{T+1} & =0
\end{aligned}
$$

\footnotetext{
${ }^{5}$ This relates closely to the discussion on durable goods and inter-temporal household optimization discussed, for instance, in Deaton and Muellbauer (1980), Jacoby and Skoufias (1997), Foster (1995) and Dercon and Krishnan (2000).
} 
Here $u$ and $v$ are concave in each of its arguments. The inter-temporal budget constraint, Equation (2) links asset levels $A_{t+1}$ at $t+1$ with initial assets $A_{t}$, private spending on educational inputs $z_{t}$, income $y_{t}$ and the consumption of other goods, $X_{t}$. The price of educational inputs is the numeraire, the price of other consumption goods is $P_{t}$ and $r$ is the interest rate. The production function constraint, Equation (3) dictates how inputs are converted to educational outcomes and the boundary condition, Equation (4) requires that at $t=T$, the household must have zero assets so that all loans are paid back and there is no bequest motive. ${ }^{6}$

In this formulation credit markets are perfect so that there are no bounds on $A_{t+1}$ apart from Equation (4); the perfect credit market assumption is relaxed in our discussion on the impact of liquidity constraints below. Moreover, households choose only the levels of $X_{t}$ and $z_{t}$ so that school inputs $\left(w_{t}\right)$ are beyond its control. At the time the household has to make its decision, it knows the underlying stochastic process governing $w_{t}$ but not the actual level. In other words, we assume that school inputs are a source of uncertainty in the model-for simplicity the only source. This assumption is retained throughout the theoretical discussion, but is later relaxed in the empirical test, where we allow for unobserved time-varying characteristics of the household that may influence school inputs.

Maximization of Equation (1) subject to Equation (2) and Equation (3) provides a decision rule related to $T S_{t}$, characterizing the demand for cognitive achievement. To arrive at this decision rule, we define a price for cognitive achievement as the "user-cost" of increasing the stock in one period by one unit, i.e., the relevant (shadow) price in each period for the household. Once such a price is defined, the program is transformed into a standard consumer optimization problem (see for instance, Deaton and Muelbauer 1980).

To define this price, note that if cognitive achievement could be bought and sold at the price, $v$, households would pay $v$ in the first period to buy one unit. In the next period, they could then sell $(1-\delta)$ units (if depreciation is at the rate $1-\delta$ ) and receive the current value $\frac{(1-\delta) v}{1+r}$. Thus, the

\footnotetext{
${ }^{6}$ There are two observations regarding the form of the utility function. First, an alternative assumption, that the benefits from the child's cognitive achievement are only felt in the future, would not change the model fundamentally. If these benefits are only related to the flow of earnings in the future from the child's cognitive achievement, then the education decision becomes similar to a pure investment decision. As long as the benefits from education are concave in its arguments, the results would be similar. Note that this of course, does not imply that the steady state value of human capital will be the same in either case, but only that along the growth path first-order conditions remain unchanged (see Banerjee 2003 for a detailed discussion of steady states under different assumptions regarding the form of the utility function). Second, the utility function uses a stock as one of its arguments: We assume that households care about the level of educational achievement. The results below are unaffected if one assumes that households care about the (instantaneous) flow from educational outcomes, provided that this flow is linear in the stock.
} 
cost of holding one unit of test scores for one period is $v-\frac{(1-\delta) v}{1+r}$ and this defines the user cost. In the context of a production function, households "buy" test scores in period $t$ is by increasing $z_{t}$. Since we are interested in the cost of boosting achievement in one period only we assume that in the next period they can reduce $z_{t+1}$ to ensure that the overall stock of test scores at $t+1$ remains unchanged. The user cost, evaluated at period $t$, is then (see Appendix 1 for the derivation):

$$
\pi_{t}=\frac{1}{F_{z_{t}}(.)}-\frac{F_{T S_{t}}(.)}{(1+r) F_{z_{t+1}}(.)}
$$

Similar to the expression $\left(v-\frac{(1-\delta) v}{1+r}\right)$ derived above, the first term measures the cost of taking resources at $t$ and transforming it into one extra unit of cognitive achievement. When implemented through a production function, the price is no longer constant - if the production function is concave, the higher the initial levels of cognitive achievement, the greater the cost of buying an extra unit as reflected in the marginal value, $F_{z_{t}}($.$) . Of the additional unit bought in period t$, the amount left to sell in period $t+1$ is $F_{T S_{t}}($.$) and the second term thus measures the present value of how much of$ this one unit will be left in the next period expressed in monetary terms. Once this is defined, the standard first-order Euler condition related to the optimal path education of educational outcomes between period $t-1$ and $t$ can be derived as:

$$
E_{t-1}\left(\beta \frac{\pi_{t-1}}{\pi_{t}} \frac{\frac{\partial U}{\partial T S_{t}}}{\frac{\partial U}{\partial T S_{t-1}}}\right)=1
$$

Intuitively this expression (ignoring uncertainty for the moment) suggests that if the user-cost of test scores increases in one period $t$ relative to $t-1$, along the optimal path this would increase the marginal utility at $t$, so that $T S_{t}$ will be lower. This is a standard Euler equation stating that along the optimal path, cognitive achievement will be smooth, so that the marginal utilities of educational outcomes will be equal in expectations, appropriately discounted and priced. Finally, the concavity of the production function will limit the willingness of households to boost education fast since the cost is increasing in household inputs. Thus, under reasonable restrictions, the optimal path will be characterized by a gradual increase in educational achievement over time.

To proceed with the empirical specification we impose the following conditions on preferences and the production function:

$[\widehat{A 1}]$ Household utility is additively separable and of the CRRA form.

$[\widehat{A 2}] T S_{t}=(1-\delta) T S_{t-1}+F\left(w_{t}, z_{t}, \mu, \eta\right)$ where the Hessian of $F($.$) is negative semi-definite.$ Under $[\widehat{A 1}]$ marginal utility is defined as $T S_{t}^{-\rho}$, with $\rho$ the coefficient of relative risk aversion. Then, Equation (6) can be rewritten as:

$$
\left(\frac{T S_{t}}{T S_{t-1}}\right)^{-\rho} \frac{\beta \pi_{t-1}}{\pi_{t}}=1+e_{t}
$$


where $e_{t}$ is an expectation error, uncorrelated with information at $t-1$. Taking logs and expressed for child $i$, we obtain:

$$
\ln \left(\frac{T S_{i t}}{T S_{i t-1}}\right)=\frac{1}{\rho} \ln \beta-\frac{1}{\rho} \ln \left(\frac{\pi_{i t}}{\pi_{i t-1}}\right)+\frac{1}{\rho} \ln \left(1+e_{i t}\right)
$$

or, the growth path is determined by the path of user-costs, and a term capturing expectational surprises.

\subsection{Anticipated and Unanticipated Inputs}

A key issue is how increases in school level inputs $w_{t}$ affect the optimal path of cognitive achievement. Since school resources are not known with certainty until after households make decisions regarding their own inputs, this will depend on whether such increases are anticipated. Thus, let $w_{t}^{a}\left(w_{t}^{u}\right)$ be inputs at time $t$ that were anticipated (unanticipated) at $t-1$. In the case of anticipated increases, the effect on the path of outcomes will depend on its impact on the usercost of educational achievement at $t$, since there is no direct impact on the budget constraint (all information included anticipated inputs will have been incorporated into the budget constraint at time $t-1$ ). In particular, using the implicit function theorem with Equation (5) and assuming $[\widehat{A 2}]$, we have

$$
\frac{d \pi_{t}}{d w_{t}^{a}}=-\frac{F_{z_{t} w_{t}}}{F_{z_{t}}^{2}} \lesseqgtr 0 \text { if } F_{z_{t} w_{t}} \gtreqless 0
$$

This implies that if household and school inputs are technical substitutes $\left(F_{z_{t} w_{t}}<0\right)$, anticipated increases in school inputs at $t$ will increase the relative user-cost of boosting at $t$, resulting in lower growth of cognitive achievement, ceteris paribus, between $t$ and $t-1$, consistent with the optimal path Equation (6). Alternatively, if school and households inputs are technical complements, increases in school inputs at $t$ will increase the marginal productivity of household inputs at $t$, and through the decline in user-costs lead to higher growth in cognitive achievement along the optimal path between $t$ and $t-1$.

To clarify the dynamics between $t-1$ and $t$ further, note that there are two effects we need to distinguish. The first is due to the change in relative user-costs while the second is governed by the households desire to smooth consumption, given by Equation (6). The second effect will always provide incentives to spend more at $t-1$ to take advantage of the additional government spending at $t$. If household and school inputs are substitutes, households will optimally recognize that relative user-costs at $t$ will be higher than at $t-1$ - the implicit price of buying test scores will increase in the future. Consequently, to retain the optimal growth path of Equation (6) households will choose to increase their own spending at $t-1$. Thus, the growth in cognitive achievement will be lower relative to the case where no household responses are possible. 
In the case of technical complements, the behavioral response is exactly the opposite, since relative user-costs will be lower at $t$, households will optimally delay spending. However, in this case the user-cost and the smoothing effects move in opposite directions so that the overall growth could still be higher relative to the case where $w_{t}=0$. Comparing the two cases of complements and substitutes, household spending is thus counter-cyclical relative to government spending when household and school inputs are substitutes. When they are complements, the smoothing and the user-cost effects move in opposite directions, although in the special CRRA case that we consider here ( $\widehat{A 1}$ ) the user-cost effect is higher than the smoothing effect so that the pro-cyclicality of household inputs is maintained.

For unanticipated increases in school inputs, since households are unable to respond, they are pushed off their optimal path and the increase in educational achievement in period $t$ is given by $F_{w_{t}} d w_{t}$. What is the size of this effect compared to a similar increase in anticipated inputs? When inputs are anticipated, using (8) the change in the optimal growth path is given by

$$
\begin{aligned}
\frac{\partial\left(\Delta_{t-1}^{t} \ln T S\right)}{\partial w_{t}^{\text {anticipated }}} & =-\frac{1}{\rho}\left(\frac{\partial \ln \pi_{t}}{\partial w_{t}}\right) \\
& =\frac{1}{\rho} \frac{1}{\pi_{t}} \frac{F_{z w}}{F_{z}^{2}} \lesseqgtr 0 \text { if } F_{z w} \lesseqgtr 0
\end{aligned}
$$

For unanticipated increases the change in the growth path is give by $\ln \left(T S_{t}+w_{t}^{\text {unant }} F_{w}\right)$ which is strictly positive. Thus, the effect of an unanticipated change is higher than that of an anticipated change in the case of substitutes, and relative sizes cannot be ranked when they are complements without further restrictions on the form of the utility function. These results are summarized in Table A for the case of the CRRA.

Table A

\begin{tabular}{|l|l|l|l|l|l|l|}
\hline Type & Inputs & $\begin{array}{l}\text { Cross- } \\
\text { Derivative }\end{array}$ & $\begin{array}{l}\text { Spending at } \\
\mathbf{t}-\mathbf{1}\end{array}$ & $\begin{array}{l}\text { Spending at } \\
\mathbf{t}\end{array}$ & $\begin{array}{l}\text { Effect on } \\
\text { Growth }\end{array}$ & $\begin{array}{l}\text { Relative } \\
\text { Ranking }\end{array}$ \\
\hline A & Anticipated & Substitutes & Increases & Decreases & Lower & A $<\{$ B,C,D $\}$ \\
\hline B & Anticipated & Complements & Decreases & Increases & Higher & B $>$ A \\
\hline C & Unanticipated & Substitutes & Unchanged & Unchanged & Higher & C $>$ A C C=D \\
\hline D & Unanticipated & Complements & Unchanged & Unchanged & Higher & D $>$ A; C=D \\
\hline
\end{tabular}

We stress that increases in outcomes due to unanticipated inputs (in the case of substitutes) are sub-optimal; household education spending will be higher than that justified by the decline in the user-cost of boosting educational achievement. Consequently, in the next period, the household will restore itself to the optimal path using the "correct" user-cost. However, since cognitive achievement is a durable the increase in outcomes will not be entirely undone, since incentives 
exist to maintain the stock at a higher level. It is important to realize therefore that the distinction between anticipated and unanticipated inputs has greater relevance for identification purposes than it has for policy - although unanticipated inputs lead to larger increases in cognitive achievement in the current period, this will be smoothed out subsequently.

\subsection{Credit Constraints}

A straightforward way to incorporate credit constraints is to assume that any point in time assets have to be nonnegative, i.e., credit is impossible unless fully collateralized $\left(A_{t} \geq 0\right)$. The definition of the user-cost remains unaffected so that the main impact is that credit constraints may limit the ability to equate appropriately discounted and priced marginal utilities. More specifically, let $\lambda_{t}$ be the multiplier linked to the non-negativity constraint of carrying over assets between $t-1$ and $t$, then the optimal path, linking $t-1$ and $t$, can be defined as:

$$
\frac{\partial U}{\partial T S_{t-1}}=E_{t-1}\left(\beta \frac{\pi_{t-1}}{\pi_{t}} \frac{\partial U}{\partial T S_{t}}\right)+\lambda_{t}
$$

in which a binding credit constraint $\left(\lambda_{t}>0\right)$ would result in higher marginal utility at $t-1$ (lower educational achievement), than what would have been implied without credit constraints $\left(\lambda_{t}=0\right)$ - see also Equation (6). What is the impact of unanticipated and anticipated changes in $w_{t}$ in this case? First, the impact of unanticipated changes in unaffected: since no behavioral response is possible, the effect still works through the production function of cognitive achievement. A difference here is that with binding credit constraints the effect might bring the household closer to its unconstrained optimal path by alleviating the credit constraint. The impact of anticipated changes now works via two effects. First the effect through the change in user-costs has exactly the same impact as before. Second, there is a further effect through the budget constraint: since fewer household resources are required than before to achieve the same level of educational achievement, this would alleviate the budget constraint (i.e., reduce the shadow cost of the constraint, $\lambda_{t}$ ).

The size of the overall effect on cognitive achievement would depend on the income effects related to the alleviation of the budget constraint. If the reduction in credit constraints leaves spending on private inputs unaffected (so that no more other goods are consumed despite the relaxation of the budget constraint), then the impact would be indistinguishable from unanticipated changes. However, in the more plausible case that other goods are normal, in general, the effect of the anticipated relative to unanticipated changes will retain the same ordering (i.e., anticipated changes have a lower (higher) effect if school and household inputs are substitutes (complements) with the usual caveat: see our discussion on the relative ranking of growth effects in the case of complements. 


\subsubsection{Summary}

The key results of this section can thus be summarized as follows:

1. When household and school inputs are substitutes, an increase in anticipated inputs at $t$ will lead to an increase in household inputs at $t-1$, a decrease at $t$ and subsequently a lower rate of growth of cognitive achievement.

2. When they are complements, the opposing directions of the user-cost effect and the household's desire to smooth implies that the overall effect depends on household preferences.

3. Unanticipated inputs, on the other hand, have no impact on household inputs at $t$ and $t-1$ and thus always lead to a higher growth in cognitive achievement between $t$ and $t-1$.

4. Finally, these results remain unchanged (though attenuated) by the imposition of credit constraints under the mild assumption that other goods consumed by the household are normal.

In testing the predictions from this model using cash grants as the relevant input, we recognize that schools should optimally allocate these grants across different inputs. One way to interpret these results is that schools are constrained in what they can do and are hence unable to spend cash grants optimally. These constraints could arise either due to thin markets (for instance, in the case of teachers) or lack of scale economies (for instance, to improve infrastructure). ${ }^{7}$ The estimated equations are thus a "reduced-form" in the sense that they represent the effect of grants taking into account constrained maximization at the school level.

\section{Empirical Specification}

Our empirical strategy is based on two related tests. We first test whether household educational expenditures and school cash grants are substitutes. The theory implies that if this is the case, contemporary household funding $z_{t}$ should decline with an increase in $w_{t}$. This is a cross-sectional test - as long as the assumptions of the regression framework are maintained we should find that households matched to schools with higher cash grants spend less on their children's education. We establish that household and school inputs are technical substitutes, and so proceed to examine the hypothesis that (under the assumption of technical substitution) the impact of anticipated grants is smaller than that of an equivalent unanticipated amount. We detail each of these in turn.

\footnotetext{
${ }^{7}$ As an example, in the case of teachers, while most head-teachers complained of shortages, only in two cases were teachers hired by the school. Both turned out to be significantly worse (in terms of education and training) than government teachers, leading to considerable dissatisfaction among the community.
} 


\subsection{Testing Substitutability between Household and Cash Grants to Schools}

We estimate a generic demand model in which household spending on school-related inputs is regressed on wealth (proxying permanent income), school attributes and school grants according to the following system of equations.

$$
\begin{aligned}
\ln z_{i j} & =\alpha+\beta_{1} A_{i}+\beta_{2} \ln w_{j(\text { match } i)}^{a}+\beta_{3} \ln w_{j(\text { match } i)}^{u}+\beta_{4} X_{i}+D_{i} P_{i}+\varepsilon_{i}+\varepsilon_{j} \\
z_{i j} & =\left\{\begin{array}{c}
z_{i j}^{*} \text { if } z_{i j}^{*} \geq 0 \\
0 \text { if } z_{i j}^{*}<0
\end{array}\right\} \\
w_{j(\text { match } i)}^{a} & =\varphi+\gamma_{1} \theta_{j}+\eta_{j}
\end{aligned}
$$

In Equation (12) $z_{i j}$ is the spending by the household on child $i$ enrolled in school $j, A_{i}$ are assets owned by household of which $i$ is a member (as a proxy variable for the permanent income of the household), $w_{j}^{a}$ is anticipated grants in school $j$ that matches to child $i, w_{j}^{u}$ is unanticipated grants received by school $j, X_{i}$ are other characteristics of child $i$ and $P_{i}$ are province level dummies. The error term is decomposed into two components where $\varepsilon_{i}$ and $\varepsilon_{j}$ are child and school specific error terms respectively. Further, $z_{i j}$ itself is a censored variable; we observe $z_{i j}^{*}$ only for strictly positive values (corresponding to an enrolled child) and for cases where the optimal $z_{i j}^{*}$ is negative, we observe censoring at zero. We test $\beta_{2}<\beta_{3}=0$, i.e., households respond negatively to expected grants at the school level by cutting back their own funding, but are unable to respond to cash grants that are unanticipated.

A potential estimation problem is that our estimate of $\beta_{2}$ is inconsistent if the error in the selection equation (14) is correlated to that in the demand equation, so that $\operatorname{cov}\left(\eta_{j}, \varepsilon_{j}\right) \neq 0$. In particular, we will see that in the Zambian case, $w_{i t}^{a}=\frac{\text { Constant }}{\text { enrollment }}$, so that omitted variables that increase the probability of sending a child to a specific school as well as the unconditional (on school choice) spending on educational materials at the household level will lead to the inconsistent estimation of $\beta_{2}$. Such a problem may arise, for instance, if there are rich villages where households send their children to school but also spend more on education. The coefficient $\widehat{\beta_{1}}$ would then capture the differences in underlying wealth rather than a causal response to rule-based grants. To some extent, we control for such wealth differences by including three different wealth indicators in the regression; the household wealth index, the average wealth index for the village and the average wealth index of students attending the school. Nevertheless, we are concerned that there are other omitted variables that lead to the inconsistent estimation of response elasticities.

To address this issue, note first that if we can restrict the sample of villages to only those where there is no school choice, the extent of the selection problem is reduced considerably, although 
the parental choice of sending children to school in the first place still remains a problem. ${ }^{8}$ To address this issue, we base our identification on careful sampling taking advantage of the very high historical enrolment rates in Zambia, even in remote rural areas. Thus, we restrict attention only to those villages where the distance costs of travelling to a school other than the one surveyed are very high (more on this below) so that any potential benefits of choosing an alternative school are unlikely to outweigh the cost of transportation. Under this assumption the problem is simplified to a two-dimensional choice between schooling and no-schooling.

We then test for the weak exogeneity of $\ln w_{s}$ using the methodology proposed by Blundell and Smith (1986). The exclusion restriction for this test is satisfied if there is a variable, $\theta_{j}$, which is correlated with $\ln w_{s}$, but not $z_{i j}$. We use the size of the eligible cohort in the catchment area and the distance to school on the assumption that these variables are correlated to enrollment, but not expenditure on the child conditional on enrollment. The Blundell and Smith (1986) test rejects exogeneity if the coefficient on the residual obtained from Equation (14) is significant in Equation (12) above. The inability to reject the null hypothesis thus establishes the exogeneity of $\ln w_{s}$ under the assumption that the size of the eligible cohort and the distance from the school are exogenous to household spending on children's schooling.

From the basic hypothesis, $\beta_{2}<\beta_{3}=0$, we can further exploit the data to test whether the grants are "truly" anticipated in the sense that households make their own decisions taking anticipated cash grants into account even before such grants are actually received. If there are schools where, at the time of the survey, $w^{a} \neq 0$ but $w_{\text {received }}^{a}=0$, a test can be based on the difference in the estimate of $\widehat{\beta_{2}}$ depending on whether we use $w^{a}$ or $w_{\text {received }}^{a}$ as the explanatory variable. ${ }^{9}$ Specifically if household decisions are based on anticipated rather than received grants, $\widehat{\beta_{2}}\left(w^{a}\right)<\widehat{\beta_{2}}\left(w_{\text {received }}^{a}\right)$ since if $w^{a}>0$ household spending will be less than what would be predicted by using $w_{\text {received }}^{a}(=0)$ as the explanatory variable. Thus, we can estimate a second equation

$$
\ln \left(z_{i}\right)=\alpha+\beta_{1} A_{i}+\widetilde{\beta_{2}} \ln w_{j(\text { received })}^{a}+\beta_{3} \ln w_{j}^{u}+D_{i} P_{i}+\varepsilon_{i}+\varepsilon_{j}
$$

and test $\widetilde{\beta_{2}}<\beta_{2}$. A rejection of the null would lead to greater confidence in the technicalsubstitution results since it would not only imply that cash grants to schools crowd-out household funding $\left(\beta_{2}<0\right)$, but further that households anticipate such grants and make their expenditure decisions before the grants are actually disbursed.

\footnotetext{
${ }^{8}$ This strategy has been used previously by Case and Deaton (1999) and Urquiola (2003) in their studies of schooling inputs and cognitive achievement.

${ }^{9}$ Satisfying the requirement that $w^{a}=0$ at the time of the survey is uncorrelated to the error term of the regression. Our identification is based on the fact that these were schools that were surveyed earlier in the month combined with delays in disbursement.
} 


\subsection{Test-Score Hypothesis}

Once we have established that household and school grants are technical substitutes, we can restrict ourselves to testing whether the impact of unanticipated grants on gains in cognitive achievement is higher than that of anticipated grants. A major concern in the parallel literature on production functions when testing for the relationship between school inputs and cognitive achievement has been the presence of unobserved child and school level heterogeneity. In the context of the Euler framework, consistent estimates may be obtained with a fairly flexible form of heterogeneity in the production function. To see this return to Equation (8) and the production function given by $[\widehat{A 2}]$. We showed previously that $\pi_{t}=\frac{1}{F_{z_{t}}(.)}-\frac{(1-\delta)}{(1+r) F_{z_{t+1}}(.)}$. Now, as long as $F_{z \mu_{i}}=0$ or $F_{z_{t}}=\mu_{i}\left(g\left(w_{t}, z_{t}\right)\right)$, so that $\ln \pi_{i t}=\ln \pi_{t} \eta_{i}$, the unobserved heterogeneity embodied in $\mu_{i}$ is eliminated from the estimating equation. This formulation is then sufficient to ensure that the path of user-costs is defined only in contemporaneous variables and is unaffected by fixed heterogeneity and past school achievement. ${ }^{10}$ Assuming identical risk preferences, an empirical specification consistent with (8) can then be written as:

$$
\ln \left(\frac{T S_{i t}}{T S_{i t-1}}\right)=\alpha_{o}+\alpha_{1} \ln w_{i t}^{a}+\alpha_{2} \ln w_{i t}^{u}+\alpha_{3} \Delta X_{t}+\epsilon_{i t}
$$

in which $w_{i t}^{a}$ and $w_{i t}^{u}$ are anticipated and unanticipated input changes, in this paper proxied by flows of funds, while $\Delta X_{t}$ reflects all other sources of changes in the user cost between $t$ and $t-1$. The core prediction is that the marginal effect of anticipated is lower than unanticipated funds when household and school inputs are substitutes. This prediction is unaffected by the presence of credit

\footnotetext{
${ }^{10}$ How restrictive is this particular formulation of the production function? Note first that we can either write the production function as

$T S_{i t}=(1-\delta) T S_{i t-1}+\beta_{1} w_{t}+\beta_{2} z_{t}+\beta_{3} \mu_{i}+\beta_{4} \eta_{j}$

or as

$T S_{i t}=(1-\delta) T S_{i t-1}+f\left(w_{t}, z_{t}, \mu_{i} \eta_{j}\right)$ if we make sure that $F_{z_{t}}=\mu_{i}\left(g\left(w_{t}, z_{t}\right)\right.$. We can compare this to three popular specifications used in the literature on the estimation of production functions for cognitive achievement, discussed in Todd and Wolpin (2003). The first, the contemporaneous specification has no role for either past levels of cognitive achievement or for the possibility that household inputs $z_{t}$ will be correlated to unobserved school and child level variables. The production function that we use here allows for both of these possibilities. The second specification, which has been widely used in the recent past is the value-added specification

$T_{i t}=\beta_{1} T_{i t-1}+\beta_{2} w_{t}+\beta_{3} z_{t}$

Note that in this case, the unobserved heterogeneity is assumed to enter only at time 0 so that $T_{i 0}=\mu_{i}$ - the child's mental "endowment" leads to a fixed increase in test scores, instead of an incremental increase in every period. A more general form is given by the cumulative specification where

$T_{i t}=\beta_{1} T_{i t-1}+\beta_{2} w_{t}+\beta_{3} z_{t}+\beta_{4} \mu_{i}$

so that child endowment can affect cognitive achievement in every period. These three widely used specifications have increasing data requirements. In particular, the cumulative specification would require at least three periods of data to arrive at consistent estimates. Our specification of the production function not only allows for the cumulative specificaiton, but also allows unobserved heterogeneity to enter in a multiplicative form so that the marginal value of household inputs can depend on unobserved child and school endowments. Further, the production function also allows for the possibility that past inputs may affect current cognitive achievement through ways other than lagged achievement - specifically, as long as we maintain the additive separability of $F_{z_{t}}$ and past inputs, our user-costs will remain unaffected. The immense flexibility in the form of the production function for cognitive achievement that the Euler framework allows for is then a major advantage over attempts to directly estimate such relationships.
} 
constraints, even though $\alpha_{1}$ is likely to be larger in that case.

The first econometric concern relates to the identification of anticipated and unanticipated cash grants. In the data anticipated grants are well identified - such grants are based on a legislated rule and a detailed tracking (implemented in the survey itself) confirms that schools receive exactly the amount stipulated. Our interpretation of unanticipated grants may be more problematic since time-series data on cash grants, which could be used to calculate deviations from the mean, are not available. We assume that grants other than the anticipated amount, which are determined at the discretion of the District Education Office, are unanticipated. This would probably overstate the unanticipated component - schools could have been informed previously of such grants, or there could be differential expectations for different schools. To see how this affects our estimates, ideally we would like to estimate

$$
\ln \left(\frac{T S_{i t}}{T S_{i t-1}}\right)=\alpha_{o}+\alpha_{1} \ln w_{i t}^{a}+\alpha_{2} \ln w_{i t}^{u}+\varepsilon_{i t}
$$

but (assuming that observed anticipated grants are zero) our estimating equation is actually

$$
\ln \left(\frac{T S_{i t}}{T S_{i t-1}}\right)=\phi_{o}+\phi_{1} \ln \left(w_{i t}^{a}+w_{i t}^{u}\right)+\varepsilon_{i t}
$$

Under the assumption that $\alpha_{2}>\alpha_{1}, \alpha_{1}<\phi_{1}<\alpha_{2}$ if our construction of unanticipated grants contains little in the way of unmeasured anticipated grants or if $\alpha_{1}$ is small compared to $\alpha_{2}$. If in the extreme, all of this were (unmeasured) anticipated, $\alpha_{1}=\hat{\phi}_{1}=\alpha_{2}$. Thus, it is likely that the estimates on unanticipated grants represents a lower-bound of the true effect. ${ }^{11}$

The second concern is potential inconsistency in our estimate of $\alpha_{2}$ if $\operatorname{cov}\left(\ln w_{i t}^{u}, \varepsilon_{i t}\right) \neq 0$, possibly arising from dynamic heterogeneity (time varying school or district-specific effects). ${ }^{12}$ This may be the case for instance if there is a change in a school-level variable that leads, on one hand, to greater unanticipated grants and, on the other hand, to higher learning gains (the introduction of

\footnotetext{
${ }^{11}$ Ignoring terms involving $\varepsilon_{i t}$ (which vanish in the expectation) and assuming deviations from means of each term:

$\hat{\phi_{1}}=\alpha_{1} \frac{\sum \ln \left(w_{i t}^{a}+w_{i t}^{u}\right) \ln \left(w_{i t}^{a}\right)}{\sum\left[\ln \left(w_{i t}^{a}+w_{i t}^{u}\right)\right]^{2}}+\alpha_{2} \frac{\sum \ln \left(w_{i t}^{a}+w_{i t}^{u}\right) \ln \left(w_{i t}^{u}\right)}{\sum\left[\ln \left(w_{i t}^{a}+w_{i t}^{u}\right)\right]^{2}}$

Using the assumption $\alpha_{2}>\alpha_{1}$ and the fact that ln is concave in its arguments, it follows that:

$\hat{\phi}_{1}>\alpha_{1}\left(\frac{\sum \ln \left(w_{i t}^{a}+w_{i t}^{u}\right) \ln \left(w_{i t}^{a}\right)}{\sum\left[\ln \left(w_{i t}^{a}+w_{i t}^{u}\right)\right]^{2}}+\frac{\sum \ln \left(w_{i t}^{a}+w_{i t}^{u}\right) \ln \left(w_{i t}^{u}\right)}{\sum\left[\ln \left(w_{i t}^{a}+w_{i t}^{u}\right)\right]^{2}}\right)>\alpha_{1}$

Also, $\hat{\phi}_{1}<\alpha_{2}$ iff $\alpha_{2}>\alpha_{1} \frac{\sum \ln \left(w_{i t}^{a}+w_{i t}^{u}\right) \ln \left(w_{i t}^{a}\right)}{\sum \ln \left(w_{i t}^{a}+w_{i t}^{u}\right)\left[\left(\ln \left(w_{i t}^{a}+w_{i t}^{u}\right)-\ln \left(w_{i t}^{a}+w_{i t}^{u}\right) \ln \left(w_{i t}^{u}\right)\right]\right.}$.

Thus the relationship between $\phi_{1}$ and $\alpha_{2}$ depends both on the extent of mis-measurement as well as the ratio of $\alpha_{2}$ to $\alpha_{1}$. In the case where mis-measurement is high and $\alpha_{1}$ is high, $\phi_{1}$ can overshoot the true impact of unanticipated grants. The independent results on household substitution and the discussion of Section 5.3 below suggest both that $\alpha_{1}$ is small and that any unmeasured anticipated component is small or non-existent.

${ }^{12}$ Note though that omitted variable bias due to heterogeneity of fixed characteristics, which normally plague cross-sectional estimates, are accounted for through the Euler framework.
} 
a highly motivated teacher who both searches for such funds and teaches exceptionally well is an example). With such omitted variables, our estimate of the impact of unanticipated grants would be inconsistent.

We correct for this problem through an instrumental variables strategy. From the Euler frame-

work, any variables at $t-1$ are available for use as instruments since such information will have been incorporated into the decision process. In addition we also use variables that were unknown at $t-1$ but had an impact on unanticipated grants at $t$. In particular, based on the detailed tracking of funds, we use per-pupil grants that the district office received from external (non-governmental) sources, allocated without any consultation with the offices.

For our instrumentation strategy to be valid, we require that the instrumental variables are positively correlated with the amount of unanticipated funds received, but are not correlated with the gain in cognitive achievement over the year. These requirements are likely to be satisfied with our choice of instruments. First, the amount of such grants boosts the overall funds available at the district level and hence the unanticipated funds passed on to schools. Simultaneously, since such funds arrive from external sources, it is unlikely that districts were able to actively influence the amount of cash grants that they would receive. This addresses our main concern that there might have been changes at the district level such that districts that received more grants were also more likely to "place" this in a targeted manner. Consequently, our strategy of using district-level aggregates combined with interactions of lagged stock variables at the school-level isolates that portion of unanticipated grants that are uncorrelated to the error term in Equation (16) above.

Finally, our results are reported at the school level. Since this is a straightforward linear aggregation, there is no reason to expect results to change; simultaneously, we are better able to handle the clustering of errors at the level of the district. To ensure that the sample remains the same, we compute school level scores only for those students who were present in both years for the test.

\subsection{Other Econometric Concerns}

There are two other specific concerns that arise due to the specific nature of our data. We briefly detail our strategy in dealing with each of these below.

\subsubsection{Treatment of Zero Cash Grants}

A large number of schools receive zero unanticipated grants in the sample. Since the estimation is based on the log transformation, we need to modify this variable in order for the log to be defined. 
Moreover the problem arises both when cash grants are explanatory (in estimations of the impact on cognitive achievement) as well as dependant variables (in the first stage of our instrumentation strategy). We address each case in turn.

When cash grants are used as explanatory variables, we use a modification of the method developed by Johnson and Rausser (1971) to derive the optimal constant to be added on to zero values. The basic intuition behind this approach is that the constant should be chosen so that the estimated relationship between cash grants and cognitive achievement is identical for both schools with zero and non-zero cash grant values (dealing with potential selection issues through the IV strategy above). In particular, we can treat the sample of schools as two separate samples consisting of $m$ observations of zero grant values and $n-m$ observations of positive grant values. The regressions can then be represented as

$$
\begin{aligned}
\ln \left(\Delta T S_{i}\right) & =\delta_{1} \ln \left(X_{i}+k\right)+\varepsilon_{i} \\
i & =1,2, \ldots, m \\
\ln \left(\Delta T S_{i}\right) & =\delta_{2} \ln \left(X_{i}\right)+\varepsilon_{i} \\
i & =m+1, \ldots, n
\end{aligned}
$$

and $k$ is estimated under the restriction that $\delta_{1}=\delta_{2}$. In addition to presenting estimated coefficients based on the estimated $\widehat{k}$, we also present robustness tests based on estimated coefficients when the unanticipated grants are treated as dummy variables (i.e., making a distinction only between those who received and those who did not). The results are robust to these alternative specifications.

For the case where cash grants are the dependant variable, we estimate a hurdle model (Wooldridge 2001) where the probability of receiving such grants is estimated separately from the amount received conditional on receipt. Under the assumption that the dependant variable, $y$, is distributed log-normally conditional on $y>0$, the maximum likelihood estimate of the unconditional $E(y)$ is

$$
E(y \mid x)=\exp \left(x \beta+\frac{\sigma^{2}}{2}\right) \Phi(x \gamma)
$$

where $x \beta$ is the predicted value from the OLS regression of $\ln y=\beta x+\varepsilon$ (restricted to $y>0$ ) and $\Phi(x \gamma)$ is the predicted probabilities estimated from a probit. In this instance, a hurdle model is preferable to the Tobit since the latter requires the probability of receipt as well as the amount received (conditional on receipt) to be governed by the same process. Contrary to this, the hurdle allows for these processes to differ, so that in the predicting equations the process of determining which schools receive positive grants is separate from the determination of how much the schools receive. Note that since we are interested in the $E(\ln y \mid x)$ and not $\ln (E(y \mid x))$ the above simplifies 


$$
E(\ln y \mid x)=(x \beta) \Phi(x \gamma)
$$

Finally, the prediction for this hurdle model is then used in the second stage of our instrumentation strategy, with an appropriate standard error correction for the use of generated regressors (Murphy and Topel 1985).

\subsubsection{Measurement Error: Test Scores}

Our second concern relates to the treatment of test scores. Our measurement of the child's human capital, $T S_{t}$, is based on tests administered in English and Mathematics. We model scores in the test as arising from the distribution of the underlying latent variable $\left(T S_{t}\right)$ following the literature on Item Response Theory (Birnbaum 1967). This method has several advantages in that the properties of the estimated latent variables are easy to interpret and the importance of the characteristics of the test are made explicit in the estimation. Further, the maximum likelihood procedure used to estimate the latent variable generates weights that are locally-optimal in the sense that they minimize the error of classification. The latent variable, $T S_{t}$, is estimated through a maximum likelihood procedure using a structural assumption regarding the mapping between $T S_{t}$ and the probability of a correct response. The standard error of this estimate can then be computed as $\frac{1}{\sqrt{\sum_{j} I_{j}\left(T S_{t}\right)}}$ where $I_{j}\left(T S_{t}\right)$ is Fisher's information for a particular question, $j$, and the sum is over all questions in the test (see Appendix 1).

How does this error of measurement effect our estimates? To the extent that the change in $T S_{t}$ is the dependant variable in our regressions, this increases the standard error of the regression, but our estimates remain consistent and unbiased. A correction is required, however, since the error structure is now characterized by a variance-covariance matrix that violates homoskedasticity of the disturbance terms. Since the standard error of our estimate is itself a function of $T S_{t}$, the variance-covariance matrix consists of terms like $\sigma_{\varepsilon}^{2}+\sigma_{u_{i}}^{2}$, where $\sigma_{\varepsilon}$ is the regression error, and $\sigma_{u_{i}}$ the measurement error for individual $i$. We account for this by adjusting standard errors for an arbitrary error-structure due to clustering. ${ }^{13}$

\footnotetext{
${ }^{13}$ Greater efficiency can be obtained by using the standard error of the estimates to implement a (modified) variance weighted least squares estimation. However, simulations in Das and DeLaat (2003) show that the efficiency gains from doing so (compared to the robust sandwich estimator) are small - the major efficiency gains arise from the use of estimated latent variable rather than the test score itself.

A more serious problem arises if cash grants are targeted toward poorly performing schools in the base year. Measurement error in test scores implies that gain-scores are higher for schools that performed poorly in the base year (Kane and Staiger 2001, 2002). Thus improvements in cognitive achievement could arise due to mean reversion rather than a causal relationship with such grants. Although measurement error due to differences in cohorts (a major source of variation in Kane and Staiger 2002) are eliminated by retesting the same children, in the case of Mathematics the gradient between gains and initial scores is significantly negative. We find no evidence of targeting
} 


\section{Data}

\subsection{The Country Context: Education in Zambia}

Our data are from Zambia, a landlocked country with a population of 10 million, almost entirely dependant on copper for export revenues. With a decline in copper prices, there has been a commensurate decrease in income and government resources. As a result, average real per capita government education expenditure in 1996-98 was only about 73 percent of its 1990-92 level, declining further to an average of about 60 percent of this level by 1999-2000 (World Bank data based on Government of Zambia Financial Statements).

This economy-wide decline has also had an impact on educational attainment. Although Zambia outperforms other African countries with similar per capita income levels, net primary school enrolment at about 72 percent is at a historically low level, having seen some decline during the previous decade (Figures 2a and 2b). ${ }^{14}$ Both the government and households have responded to this worsening of the education profile. The government for instance initiated a Basic Education Sub-Sector Investment Program in 2000, which along with administrative changes in the delivery of educational services and restructuring of the payroll for teachers also led to some direct financing of schools through cash disbursements. While household responses are clearly harder to interpret, we will see below that parents tend to be active in their children's education with high contributions, both in terms of expenditures as well as time. It is precisely this involvement that will be exploited in our tests below.

\subsection{Sampling}

The study is based on a survey of 182 schools in four provinces of the country and was collected by the authors in 2002. ${ }^{15}$ The choice of schools was based on a probability-proportional-to-size sampling scheme, where each of 35 districts in the four provinces was surveyed and schools were randomly chosen within districts with probability weights determined by enrollment in the school. Thus, every enrolled child in the district had an equal probability of being in a school that participated in the survey.

In every school, 20 students were randomly chosen in Grade V in 2001 and an achievement test was administered in Mathematics, English and the vernacular. ${ }^{16}$ The same test was admin-

toward poorly performing schools based on observable characteristics. Targeting based on observables is addressed through the instrumentation strategy.

${ }^{14}$ These levels are similar to Kenya, higher than Congo or Mozambique, but below those typically attained in other Southern African countries (see for example, World Bank and UNESCO).

${ }^{15}$ Lusaka, Northern, Copperbelt, and Eastern provinces were surveyed. These four provinces account for 58 percent of the total population in Zambia.

${ }^{16}$ In cases with less than 20 students, all children were tested. 
istered again in 2002 to the same students leading to the construction of a two-year panel of test scores. In addition to the tests and a school questionnaire, questionnaires were administered to the head-teacher and all teachers who were teaching or had taught the tested children. These children were also asked to complete a pupil questionnaire in every year with information on basic assets, demographic information, and educational flows within the household. Further, as part of the expenditure tracking exercise, district and provincial educational offices associated with the surveyed schools were administered questionnaires detailing financial activity over the year (receipts and disbursements of cash and materials).

In addition to the school survey, household surveys were administered to 540 households in 35 villages. The choice of villages was designed to eliminate complications arising from school choice (see Section 4.1): Based on a geographical mapping of all schools, those that satisfied a "remoteness" criteria (defined as the closest neighboring school being at least $5 \mathrm{kms}$ away) were chosen as starting points for villages in the household survey. From these schools, the closest (or second closest depending on a random number) village was chosen and 15 households were randomly chosen from households with at least one child of school-going age.

Two different samples are thus used for the empirical section of this paper. The first sample (the Household Sample) is based on a subset of 35 remote schools, with data on matched school and household inputs for 540 households. Since 15 households were selected from every village, we have data on cognitive achievement for only 200 students in this sample and hence can use this data only to test the resource-substitution hypothesis. The larger sample of 182 schools provides data on changes in cognitive achievement for 2,600 students with matched data on school, teacher and head-teacher attributes but not on household expenditures. This sample is used to test the TestScore hypothesis. Finally, data from provincial and district levels are used to provide instrumental variables for the Test-Score Hypothesis. Table B clarifies the use of our data.

Table B

\begin{tabular}{|c|c|c|c|}
\hline Sample & Questionnaires & Learning Achievement & Used For \\
\hline Household & Household Questionnaire & $\mathrm{X}$ & Substitution Hypothesis \\
\hline \multirow[t]{2}{*}{ School } & $\begin{array}{l}\text { School Funding, School } \\
\text { Attributes }\end{array}$ & 3,600 students in 2001 & \\
\hline & $\begin{array}{l}\text { Head Teacher and Teacher } \\
\text { Attributes }\end{array}$ & 2,700 re-tested in 2002 & Test Score Hypothesis \\
\hline Tracking & $\begin{array}{l}\text { District/Province Level } \\
\text { Funding }\end{array}$ & $\mathrm{X}$ & Instrumental Variables \\
\hline
\end{tabular}




\subsection{Description: Schools}

Reflecting the overall decline in the education sector, schools in our sample are under some stress (Table 1a). There are over 100 children for every functional classroom, student-teacher ratios are above the Zambian guideline of 40 and there are a large number of repeaters. Moreover, for almost every variable rural areas tend to do worse than their urban counterparts and this difference is further magnified in the case of the schools chosen for the household sample. The difference is particularly marked for asset holdings where the mean value of the asset index is one standard deviation lower in rural and 1.2 standard deviations lower in remote villages compared to urban areas.

Turning to educational inputs, there are three distinct types of inputs that schools may receiveteaching inputs through new teachers or increases in staff remuneration, in-kind receipts in the form of textbooks or chalk, and cash receipts. The effect of teacher inputs is studied in some detail in Das, Dercon, Habyarimana, and Krishnan (2003). Further, during the year of the survey, schools received very little inputs in-kind - on average less than 0.05 textbooks, 0.012 desks, 0.001 chairs and 0.01 boxes of chalk were received per student. ${ }^{17}$ Consequently, the impact of the third type of inputs (cash receipts excluding teacher's salaries) on cognitive achievement forms the basis for this study.

Contrary to the poor record of in-kind receipts, most schools had received some cash and this is explored further in the "cash grants" rows of Table 1a. There were two kinds of cash receipts that schools could receive. Rule-based grants were received under legislation that grants $\$ 600$ (\$650 in the case of schools with Grades 8 and 9) to every school irrespective of enrollment. We treat this as "anticipated" in our analysis. The second kind, discretionary grants were disbursed to schools at the discretion of the District Education Office as well as external donors. We treat this as "unanticipated" recognizing that this may overestimate the "true" unanticipated component of cash grants .

One concern is that legislated allocations may have little to do with received grants and our treatment of such grants as "anticipated" is thus incorrect. ${ }^{18}$ A tracking exercise presents some encouraging results on this front (Table 1a, Cash-Grant Characteristics). In three out of the four provinces, over 93 percent of the schools surveyed received exactly the amount allocated. In the

\footnotetext{
${ }^{17}$ This was largely due to problems in the planning department of the Ministry of Education coupled with problems in procurement, rather than due to the lack of funds (less than 60 percent of the allotted budget was actually used during the fiscal year).

${ }^{18}$ In the case of Uganda for instance, Ablo and Reinikka (2000) showed that less than 30 percent of the allocated capitation grant was received by schools.
} 
fourth province, Lusaka, this percentage dropped to 71 percent and this was attributed to delays in disbursement. Based on receipts in the previous year as well as interviews with head-teachers and district officials, it appeared that the remaining schools would receive the allocated disbursement shortly after the survey. ${ }^{19}$ It is precisely this delay that is exploited in drawing the distinction between $w^{a}$ and $w_{\text {received }}^{a}$ in Equation (15) above (details of the tracking exercise are in Das and others 2003). Note also that the per-pupil rule-based grants are fairly high in absolute amounts ranging from 60 percent of household educational expenditures for the poor to 45 percent for the rich.

In contrast to the regularity of rule-based allocations, the probability of receiving discretionary grants was much lower (24 percent). Conditional on receipts such funds tend to be either very small or extremely large - the inter-quartile range for log discretionary grants ranges between 6 and 10 log kwacha per pupil with a coefficient of variation greater than 6 . Finally, variables such as school or pupil characteristics have almost no predictive power in explaining the distribution of discretionary funds - less than .05 percent of the variation in such funds can be explained through differences in student composition, characteristics of teachers (head-teachers) or the availability of educational resources in the school.

The last point also addresses the potential targeting of discretionary funds (Table 1b). At least on the basis of observable outcomes, there is little difference between schools that received discretionary funds vis-à-vis those that did not. Although schools that received such funds tend to have students who are marginally wealthier and are located closer to the district office, these differences are not significant at the 10 percent level. Moreover, there is no difference in baseline scores between schools that received discretionary funds and those that did not. ${ }^{20}$

Thus, on the one hand rule-based allocations are clearly demarcated and defined, and schools receive the amount stipulated. On the other hand, discretionary funds are more volatile - less than one quarter of all schools receive such funds, and even conditional on receipts, the amount received varies dramatically. Further, such funds do not seem to have been allocated in a targeted fashion, at least on the basis of observable school and student characteristics. It is precisely this difference that forms the basis for our division of cash grants into anticipated and unanticipated components.

\subsection{Description: Households}

To complete our description, it is also instructive to examine household funding of school inputs in comparison to the funding received from the government. In particular, if household educa-

\footnotetext{
${ }^{19}$ This was checked and confirmed in the case of some schools in Lusaka province, two months after the survey.

${ }^{20}$ This addresses the issues of mean reversion discussed earlier.
} 
tional expenditures are small compared to school grants, anticipated grants may play a role in the alleviation of credit constraints at the household level (although our empirical test would remain valid). Figure 3 explores the importance of different funding sources for educational expenditure, disaggregated by schools that received high/low anticipated cash grants (with the cutoff at the median).

In both types of schools, household expenditure accounts for a large share of total (public and private) spending on education, ranging from 25 percent to 33 percent across schools that received high/low cash grants. The other significant expenditure share is accounted for by teachers salaries (roughly 50 percent in both cases); ignoring this component implies that household expenditure accounts for between 50 percent and 60 percent of total available expenditures. Since the household data is based on a sample of remote schools that tend to be poorer, this percentage represents a lower bound on the actual share of household expenditure in total funding. Clearly then, even in remote and poor areas, households represent an extremely important component of educational funding and it is likely that they have sufficient leeway to adjust for changes in expected grants at the school level.

In anticipation of our results, Table 2 then looks at key household and school variables for schools with high/low enrollments (and hence low/high anticipated grants). The first row (matching success) shows the percentage of children in the primary age group who were successfully matched to the surveyed school, verifying our assumption of no school choice through the choice of the sample. For both high/low grant schools, matches are above 95 percent, but there is a (significant) 3 percent difference suggesting that endogenous enrollment may still be an issue.

The next two rows describe school cash grants and household expenditures. There are large differences in the means of two groups, although interestingly total funding is roughly equivalent, at K24,000 in low and K22,000 in high grant schools. The other rows in the table correspond to observable components of schools and households. For a number of important variables (household's asset indices, mother's/father's education and village enrollment) there is no significant difference between the two categories of cash grants. Moreover, in cases where differences are significant (percentage with mother/father at home) the direction is the opposite of what we would expect if enrollment was endogenous to villages and schools - high enrollment (low grant) schools tend to have fewer children with parents at home and report fewer visits from teachers to the household.

These statistics thus suggest that (a) there are significant differences in household contributions across low/high cash grant schools, and the null hypothesis that total funding is the same cannot be rejected (b) while there are some differences in observable household components across the two 
categories, these differences tend to be small or of the wrong sign. Our results on the substitutability of household and school cash grants verifies these broad results in a structured manner.

\subsection{Description: Cognitive Achievement}

Finally, our data on cognitive achievement are based on tests administered by The Examination Council of Zambia in Mathematics and English for the same sample of children in 2001 and 2002, following the sampling scheme described above. These children were initially tested in Grade V and in 2002 they were tested in the grade that they were currently enrolled in. Although we should hence have a two-year panel of test scores for 3,500 children (since there were less than 20 children in Grade $\mathrm{V}$ in some schools), attrition in the data set leads to a smaller sample of 2,587 children. This drop is attributable to a number of factors including school-transfers/drop-outs (30 percent), absence on the day of the test (50 percent) and data issues arising from the inability to survey some schools or adequately complete pupil rosters (20 percent). We find some differences in original scores, with those who were unable to take the second test reporting significantly lower English and Math scores in the first year (0.11 and 0.19 standard deviations. respectively), but do not find any systematic pattern in attrition across schools receiving different amounts of anticipated/unanticipated cash grants.

Turning to learning gains over the year, students on average were able to answer 3.2 questions more in Mathematics from a starting point of 17.2 correct answers (from 45 questions) and 2.4 more in English starting from 11.1 correct answers (from 33 questions). In terms of our latent distribution, children gained on 0.42 standard deviations in Mathematics and 0.40 in English. Thus, after one year of teaching students were able to increase their scores by 6 percent and 7.5 percent in Mathematics and English, respectively.

Finally, Figure 4 shows the characteristics of the Mathematics and the English test with respect to the standard error of our latent score distribution. For both Mathematics and English, the test was "too-hard" in the sense that children at the lower end of the distribution have (much) higher standard errors than those above the mean. Further, the English test was better designed than the Mathematics with lower estimated standard errors at all points of the distribution. Following from our previous discussion we thus expect considerable noise in our estimates, but also lower standard errors for our cognitive achievement results based on the English compared to the Mathematics test. 


\section{Results: Does Household Spending Substitute for School Cash Grants?}

Our main interest is the estimation of Equations (12) and (15). To recapitulate, Equation (12) estimates the relationship between household and school grants using anticipated grants that had already been received at the time of the survey $\left(w_{\text {recieved }}^{a}\right)$. Equation (15) then uses the anticipated grants $\left(w^{a}\right)$ instead (whether received or not at the time of the survey); if households truly anticipate such grants, the elasticity of substitution based on the second equation should be greater than the first.

The estimation results are presented in Table 3. For every estimated equation there are two specifications. The first is the Tobit specification where the sample includes all school going age children and educational expenditures on children who are not enrolled is defined to be zero. We may be concerned that the Tobit specification does not entirely capture the error structure of (12), with clustering at the village level. To account for this clustering, we also present estimates from a random effect Tobit specification that accounts for such clustering. Columns (1) and (2) thus report results from Equation (12), and (3) and (4) from Equation (15). Table 4 then interprets these coefficients as the marginal impact (computed at the mean of the regressors) and the probability that the dependant variable is uncensored.

The results are as predicted and robust to the sample and specification used. Using $w_{\text {received }}^{a}$ as the regressor, the estimated elasticity of substitution for anticipated grants is always negative and significant $\left(\widehat{\beta_{2}}\left(w_{\text {recieved }}^{a}\right)<0\right)$ and ranges from -0.34 (Tobit) to -0.37 (Random Effects Tobit). Further, $\widehat{\beta_{2}}\left(w^{a}\right)<\widehat{\beta_{2}}\left(w_{\text {recieved }}^{a}\right)$ with the elasticity of substitution increasing to -0.46 (Tobit) to -0.52 (Random Effects Tobit) suggesting that households truly anticipate these cash grants and make their expenditure decisions prior to their actual receipt. Moreover, using $w^{a}$ as a regressor, the coefficient of unanticipated grants is small and insignificant $\left(\widehat{\beta_{3}}=0\right)$. For the specification where $\widehat{\beta_{3}}<0$, the size of the coefficient is less than half that of $\widehat{\beta_{2}}\left(w_{\text {recieved }}^{a}\right)$ suggesting that there may have been some household responses to unanticipated funding, but this was relatively small compared to funding that was anticipated..$^{21}$

These results present strong evidence for a high elasticity of substitution between anticipated grants and household funding, and support the hypothesis that households make their educational funding decisions prior to the actual receipt of such grants. Further, households do not respond to unanticipated grants - despite the comparability of such grants (in amounts) to the anticipated equivalent, there is little evidence that households alter their own behavior as a response.

\footnotetext{
${ }^{21}$ Note that to the extent that households did respond to unanticipated funding as well, this would imply that our coefficient on such funding in the test-score regression is an underestimate of the true production function parameter.
} 
Our main worry with these results is the possibility of omitted variable bias that arises due to the close link between anticipated grants and enrollment and this is addressed in Columns (5) and (6). Following the strategy outlined in Section 4.2 we estimate the determinants of log anticipated funding in the first stage and use the residuals as an additional regressor in the specifications estimated under Equation (15). Using anticipated funding in the first stage with Equation (15) as the second stage, the coefficient on the residual is insignificant at the 15 percent level confirming that the log of anticipated funding is exogenous to child level educational expenditures and estimated coefficients thus represent a causal relationship (Columns 5 and 6, Table 3). ${ }^{22}$

\section{Results: Test Score Hypothesis}

\subsection{Graphical Evidence}

The results in the previous section provide strong evidence that school grants and household funding are indeed substitutes - greater cash grants given to the school reduces the amount spent by the household. As discussed in Section 3.3, when school and household inputs are technical substitutes, the impact on learning gains of unanticipated is larger than that of anticipated inputs.

Figure 5 explores this relationship through non-parametric plots of the relationship between cash grants and gain in cognitive achievement. The figure on the left shows the (annual) change in cognitive achievement in the subjects of Mathematics and English plotted against (log) unanticipated grants while the relationship between gains in cognitive achievement and (log) anticipated grants. In both figures, the left axis shows the density of cash grants plotted on a histogram while the right axis depicts learning gains in Mathematics and English, plotted against the log grants. The figure verifies our basic hypothesis: learning gains are higher for unanticipated compared to anticipated grants. In the case of Mathematics there is a gain of almost 0.2 standard deviations and for English 0.15 standard deviations moving from the minimum to maximum unanticipated grants. Moreover, there is no discernible pattern in the case of Mathematics and a decline in the case of English for anticipated grants.

Figure 5 also suggests reasons for high standard errors in our estimation procedure. From the histogram for unanticipated grants it is clear that the distribution is marked by a large percentage of schools that receive zero combined with substantial variation among those that do receive positive amounts. Consequently, large variation in learning gains among the non-receivers might decrease the precision of the estimated relationship between cash grants and learning gains. Further, there

\footnotetext{
${ }^{22}$ Note that this test is valid only if anticipated rather than received funding is used in the first stage. If received funding is used as the dependant variable we have imposed high enrollment for schools that received zero funding at the time of the survey in combination with a lower than expected expenditure and this would lead to a rejection of the weak exogeneity of $\ln w^{a}$.
} 
appear to be differences in the precise functional form between Mathematics and English. For Mathematics small amounts of unanticipated grants have a low impact on learning achievement while for English such investments have an impact but decreasing returns set in quickly at higher levels. Although ideally we would like to estimate these non-linearities, our sample of 42 schools that receive positive amounts precludes further sub-division. Thus, we account for non-linearities through the inclusion of a quadratic term for unanticipated grants in Equation(16) and check for robustness using a dummy variable for schools that received non-zero unanticipated grants.

\subsection{OLS Results}

Table 5 shows the results for English and Mathematics for four different specifications where all estimations are at the school level. ${ }^{23}$ The first specification (column 1 for English and column 2 for Mathematics) is the most parsimonious and includes only anticipated and unanticipated grants in the estimation. The next two columns then include four additional explanatory variables- a dummy for rural is included to proxy for "shifters" and three variables that capture potential changes in user-costs - whether the head-teacher has changed, whether the head of the parentteacher association changed and the difference in PTA fees. The third specification (columns 7 and 8 ) include as variables the portion of anticipated funds that had actually been received by the time of the survey, as in Section 6 above.

For all specifications we find that the coefficient on anticipated grants is small and insignificant (except for the negative and significant value in column 7 for English), marginally more so in the case of English compared to Mathematics. For English the coefficient on the linear term of unanticipated grants is always positive and significant, and for the quadratic term negative and significant. For Mathematics the results are not as sharp; the coefficient on unanticipated grants is smaller and insignificant in three specifications, but is significant when unanticipated grants are treated as a dummy variable. Treating cash grants as a continuous variable, these results imply that the marginal impact of (log) grants on cognitive achievement at the mean is .048 standard deviations for English and .029 for Mathematics, representing 12.5 percent and 7 percent of the annual gain in learning. The results from the dummy specification imply that schools receiving non-zero unanticipated grants improve their learning by 0.12 (English) and 0.09 (Mathematics) standard deviations, which corresponds to approximately one-third of the average gain through the year.

\footnotetext{
${ }^{23}$ Since the estimated equation is linear, averaging over children should have no impact on the estimated coefficients. In fact, child-level regressions show similar coefficients but the significance is reduced when the regression is clustered at the school rather than the district level. All coefficients retain their significance at least at the 10 percent level of confidence. Further, the results from the IV estimation are identical both in the size and the significance of the coefficients. These differences may arise due to the clustering of errors at both the school and the district level.
} 
We make two observations on the set of estimated coefficients. First, returning to the standard error of our latent score distribution, it is clear that the measurement error in the case of Mathematics is much larger than that for English. This would suggest that our estimates our more precise for the latter and could explain the significant findings for English but not for Mathematics. Second, in Figure 5 the differences in English are driven primarily by schools receiving zero and positive grants while those in Mathematics are driven by the difference between those receiving small and large amounts. In using the log specification, the optimal constant added to those with zero unanticipated grants is only K3.73. Given the steep gradient of the logarithm function near zero, the addition of a small constant implies that the estimated relationship is driven almost entirely by the difference between the "zero" and the "non-zero" group rather than by the "low positive" and the "high positive" receivers. Consequently, in the case of Mathematics, the positive relationship between the low and the high group is overwhelmed by the flat portion before with the reverse for English. However, when we use a dummy variable for whether or not the school received any unanticipated funds as a regressor, both coefficients are significant and positive (and fairly close to each other) since we "average" out these functional differences.

\subsection{Results and Comparison}

The final set of results we present corrects for the potential placement problem through the instrumentation strategy detailed above. The first stage from these results are presented in Table 6 , and the results on learning changes using the instrumented unanticipated funds in Table 7. In the first stage, we find that the grants that the district received from external sources significantly impacts on the amount of unanticipated funds that a school will receive; the only other significant variable is whether the district was one that was heavily contested in the run-up to the election the same year as the survey. Together, the lagged variables and the funds received through external sources account for 50 percent of the variation in unanticipated funds at the level of the school, conditional on receipt. For the second part of the hurdle model, the probability that a school receives any cash grants is determined largely by the status of the school as one that was eligible to receive funds from an external donor program administered by the United Nations since 2000.

Turning to the instrumented estimation results, we find that in all cases, there is an increase in the linear and a decrease in the quadratic term of the estimated equation. Moreover, for both English and Mathematics, the coefficients on unanticipated funds and unanticipated funds squared are always significant, while on anticipated funds the coefficients continue to remain small and insignificant. However, due to the quadratic formulation, it is not immediately apparent that these

findings can be interpreted as evidence of positive-placement whereby schools that were likely to do worse received more grants. To formally evaluate our hypothesis that the marginal impact of 
unanticipated is greater than that of anticipated grants, Table $\mathrm{C}$ presents results of Wald tests at various points of the sample range.

Table C

Subject and Estimation Strategy Test Rejects Equality of Coefficients Evaluated at (p values)

$\begin{array}{llllll} & \text { Sample mean } & 25 \text { th } \% \text { tile } & \text { Median } & 75 \text { th } \% \text { tile } & 90 \text { th } \% \text { tile } \\ \text { English (OLS) } & 5 \% & 5 \% & 5 \% & 5 \% & >10 \% \\ \text { English (IV) } & 1 \% & 1 \% & 1 \% & 5 \% & 5 \% \\ \text { Math (OLS) } & >10 \% & >10 \% & >10 \% & >10 \% & >10 \% \\ \text { Math (IV) } & 10 \% & 5 \% & 10 \% & >10 \% & >10 \%\end{array}$

Since the marginal impact of unanticipated grants is given by $b_{1}+2 b_{2} X$ where $b_{1}$ is the coefficient on unanticipated, $b_{2}$ on unanticipated grants squared and $X$ the point at which the marginal value is evaluated, the Wald test takes into account the $\operatorname{var}\left(b_{1}+2 b_{2} X\right)$ given by the usual expansion. Each cell in the table shows the confidence level at which the null hypothesis that the marginal impact of unanticipated equals that of anticipated grants can be rejected. For English we find that the OLS results allow us to reject the null hypothesis at all points of the sample range at the 5 percent level, and we are unable to reject the null at the 90 th percentile. The IV results are stronger; the null hypothesis can now be rejected at the 1 percent level for the mean, the 25th percentile and the median, and the 5 percent level for the 75th and 90th percentile. For Mathematics, overall results are weaker. We cannot reject the null hypothesis at any point of the sample range for the OLS results. With instrumental variables, results are marginally better with rejections at the 10 percent level for the sample mean and median, and at the 5 percent level for the 25 th percentile.

\section{Discussion and Policy Implications}

Using data on learning achievement and non-salary cash grants to schools in Zambia we have tested a model of dynamic household optimization with the key prediction that anticipated compared to unanticipated grants will have a smaller effect on cognitive achievement if household and school cash grants are substitutes. In the case of Zambia, we find that the elasticity of substitution between household and school grants ranges from -0.35 to -0.52 . Consistent with our predictions, we then find that anticipated grants have zero impact on learning gains while unanticipated funds increase learning by 0.05 (English) and 0.025 (Mathematics) standard deviations at the mean. The estimated coefficients are likely under estimates of the true production function coefficient due to the potential contamination of unanticipated grants by anticipated components, but are robust to 
omitted variable bias arising either from school-choice or time-varying school effects. These results have implications both for estimation and policy and we discuss each of these in turn.

\subsection{Implications for Estimation}

The dominant estimation technique for estimating the effect of school inputs on cognitive achievement is based on the production function approach, where achievement (or changes in achievement) is regressed on school inputs. Following Todd and Wolpin (2003), these estimates represent the policy effect of school inputs that combines both the effect of inputs on cognitive achievement through the production function, as well as household responses to such inputs. Our use of unanticipated inputs allows the estimation of both effects separately, thus shedding more light on the process through which school inputs may or may not affect educational attainments.

For estimation purposes, it may appear that the problem in the production function approach arises due to omitted variables - if the researcher had access to both household and school expenditures in the current period, it would be possible to accurately estimate the effect of the input through the production function. While true in a static setting, this does not take into account the possibility of inter-temporal substitution in a dynamic problem. Specifically, households start responding to school inputs at the time that information regarding such inputs is revealed so that the entire history of household inputs will be required from that point onward to estimate unbiased production function parameters. The alternative approach followed in this paper is to examine the portion of inputs that arrive as exogenous shocks so that households are unable to respond in the current (or preceding) periods. In the absence of data on historical household inputs (as well as details on the revelation of information) the use of unanticipated inputs allows identification of the production function parameter with greater accuracy.

The distinction we draw between anticipated and unanticipated inputs could also account for the wide variation in estimated coefficients of school inputs on cognitive achievement (Glewwe 2002; Hanushek 2003; or Kreuger 2003) The production function framework does not separate anticipated from unanticipated inputs so that the regressor is a combination of these two different variables. The estimated coefficient is bounded below by the policy effect and above by the production function parameter; the distance from either bound depends on the extent to which the schooling inputs were anticipated or not.

There are a number of extensions that can be pursued in future research. While the use of the Euler equation framework allows us to control for heterogeneity arising from a number of sources and in a fairly flexible form, our model does require some restrictive assumptions. First, we are 
unable to control for heterogeneity due to the underlying production function or the household discount rate. Second, we are unable to allow for non-linear effects of the lagged test score and third, our specification requires the use of an additive lagged test score in the production function. The last two problems could potentially be addressed by panels that span a larger time period.

\subsection{Implications for Policy}

The argument developed here also has repercussions for educational policy. Our results do not suggest an educational policy where inputs are provided unexpectedly. Although cognitive achievement in the current period does increase with unanticipated inputs, the additional consumption now will push households off the optimal path. In subsequent periods, therefore, they will readjust expenditures until the first-order conditions are valid again - unanticipated inputs in the current period will not have persistent effects in the future (except due to the durable nature of the good).

The policy framework that is suggested under this approach involves constructing appropriate "spheres of influence". Under such a framework schooling inputs are characterized by the level of market imperfections that characterize their provision, as well as the degree of substitutability with household contributions. Inputs are then divided into two categories - those within the sphere of influence of either the government or the household.

The former would include inputs that are characterized by incomplete markets or other market failures (see Miguel and Kremer 2003 for an example of market failures due to externalities) while the latter would consist of inputs provided under competitive market conditions. Further, to the extent that the government may be worried about the inability of households to smooth human capital accumulation (for instance due to credit constraints), direct subsidies to households rather than inputs at the school level characterize the optimal policy.

What inputs may lie in the governments "sphere of influence"? An important example may be teaching inputs, whereby problems in the design of contracts (see for instance Holmstrom and Milgrom, 1991, for problems arising due to multi-tasking or Holmstrom, 1982, for problems arising due to moral hazard in teams) or the generic non-availability of trained personnel in every village could make public more efficient than private provision. Similarly, inputs that retain some aspects of public-goods and would thus be under-provided in the private market are a good candidate for government provision. Interestingly, both of these have been shown to have significant impacts on cognitive achievement (see for example, Hanushek 2001 and Banerjee, Cole, Duflo, and Linden 2003 on the importance of teachers and Glewwe and Jacoby 1994 on infrastructure).

The approach followed here of treating cognitive achievement as a household maximization 
problem with the production function acting as a constraint opens up a new avenue for research, one that explicitly recognizes the centrality of households and classifies schooling inputs into the categories discussed above. To construct the appropriate "spheres-of-influence" it would be important to characterize inputs by their degree of substitutability vis-a-vis household provision. To do so requires both the use of matched household and school surveys as well as the careful identification of surprises in the provision of inputs; in particular, long-term data on schooling inputs would allow for cleaner identification based on deviations from means, much as in the consumption literature. 


\section{Appendix 1}

Proof of 5. To define the user cost, we consider a change in $z_{t}$ and $z_{t+1}$ that increases cognitive achievement by one unit in period $t$ only. Formally,

$$
\begin{aligned}
& d T S_{t}=F_{z_{t}}\left(w_{t}, z_{t}, \mu, \eta\right) d z_{t} \\
& d T S_{t+1}=F_{T S_{t}}\left(w_{t}, z_{t}, \mu, \eta\right) d T S_{t}+F_{z_{t+1}}\left(w_{t+1}, z_{t+1}, \mu, \eta\right) d z_{t+1}=0
\end{aligned}
$$

where $F_{z_{t}}, F_{z_{t+1}}$ and $F_{T S_{t}}$ are marginal effects of the educational achievement production function with respect to household inputs in the current and next period, related to initial levels of cognitive achievement in the next period. The conditioning $\left(w_{t}, z_{t}, \mu, \eta\right)$ explicitly recognizes that these marginals will be a function of current levels of inputs as well as child and school non-time varying characteristics. To achieve this, assets are reduced in period $t+2$ by:

$$
\begin{aligned}
d A_{t+2} & =(1+r) \cdot\left(d z_{t+1}+(1+r) d z_{t}\right) \\
& =(1+r)\left(\frac{-F_{T S_{t}}(.)}{F_{z_{t+1}}(.)}+\frac{(1+r)}{F_{z t}(.)}\right) d T S_{t}
\end{aligned}
$$

which defines the user cost in the expression given by 5 .

Maximum Likelihood Derivation of the latent variable $\theta$ Following Birnbaum (1967), we follow a parametric approach and use the 3 parameter logistic to map the latent variable $T S_{i t}$ to the probability of a correct answer in question $j, P_{j}\left(T S_{i t}\right)$ so that

$$
P_{j}\left(T S_{i t}\right)=c_{j}+\left(1-c_{j}\right) \frac{1}{1+\exp \left\{-a_{j}\left(T S_{i t}-b_{j}\right)\right\}}
$$

Following IRT terminology, the parameter $b_{j}$ measures the difficulty of the item (a location parameter), $a_{j}$ measures the discrimination of the item and $c_{j}$ measures the guessing probability. We can then define the likelihood function as follows

$$
L\left(T S_{i t}, a, b, c\right)=\prod_{j} \prod_{i} P_{j}\left(T S_{i t}, a_{j}, b_{j}, c_{j}\right)^{x_{i j}}\left\{1-P_{j}\left(T S_{i t}, a_{j}, b_{j}, c_{j}\right)\right\}^{1-x_{i j}}
$$

where $x_{i j}$ is the response by individual $i$ to question $j$. Maximization of the likelihood function then gives us the required normal equations. We use a Marginal Maximum Likelihood estimation (Bock and Lieberman 1971) in combination with an Expected-Maximization (EM) algorithm (Bock and Aitkin 1980). Under this scheme, a density function is assumed for the latent variable, $f\left(T S_{i t}\right)$. This is then "integrated-out" to arrive at consistent estimates of the item parameters $\left(a_{j}, b_{j}, c_{j}\right)$. 
As the last step the item parameters are then used to calculate $T S_{i t}$. Finally, Fisher's information measure for the latent variable $T S_{t}$, can be written as

$$
\begin{aligned}
I\left(T S_{i t}\right) & =\sum_{j=1}^{J} I_{j}\left(T S_{i t}\right) \text { where } \\
I_{j}\left(T S_{i t}\right) & =\frac{\left\{P_{j}^{\prime}\left(T S_{i t}\right)\right\}^{2}}{P_{j}\left(T S_{i t}\right)\left(1-P_{j}\left(T S_{i t}\right)\right.}
\end{aligned}
$$

The standard error or our estimate $\widehat{T S_{i t}}$ is now simply $\frac{1}{\sqrt{\sum_{j} I_{j}\left(T S_{i t}\right)}}$ and by the property of ML estimators $\widehat{T S_{i t}} \sim N\left(T S_{i t}, \frac{1}{\sqrt{\sum_{j} I_{j}\left(T S_{i t}\right)}}\right)$. Note that once the structural parameters $\left\{a_{j}, b_{j}\right.$, and $\left.c_{j}\right\}$ are determined for the test in 2001, since the same test was administered again in 2002, we again identify the change in the distribution of $T S_{i t}$ without assuming a density function for 2002 . 


\section{References}

The word "processed" describes informally reproduced works that may not be commonly available through library systems.

Ablo, Emmanuel, and Ritva Reinikka. 2000. "Do Budgets Really Matter: Evidence from Public Spending on Education and Health in Uganda." Policy Research Working Paper 1926. World Bank, Washington, D.C.

Alderman, Harold, Jere R. Behrman, Shahrukh Khan, David R. Ross, and Richard Sabot. 1997. "The Income Gap in Cognitive Skills in Rural Pakistan." Economic Development and Cultural Change 46(1): 97-123.

Angrist, Joshua D., and Victor Lavy. 1999. "Using Maimonides' Rule to Estimate the Effect of Class Size on Student Achievement." Quarterly Journal of Economics 114(2): 533-575.

Banerjee, Abhijit. 2003. "Educational Policy and the Economics of the Family." Massachusetts Institute of Technology. Processed.

Banerjee, Abhijit, Shawn Cole, Esther Duflo, and Leigh Linden. 2003. "Remedying Education: Evidence from Two Randomized Experiments in India." Massachusetts Institute of Technology. Processed.

Becker, Gary, and Nigel Tomes. 1986. "Human Capital and the Rise and Fall of Families." Journal of Labor Economics 4(3):1-39.

Birnbaum, Allan. 1967. "Some Latent Trait Models and Their Use in Inferring an Examinee's Ability." In Frederic M. Lord and M. R. Novick, eds., Statistical Theories of Mental Test Score. London: Addision-Wesley Publishing Company.

Bock, Richard D., and M. Aitkin. 1981. "Marginal Maximum Likelihood Estimation of Item Parameters: An Application of an EM Algorithm." Psychometrika 46: 443-459.

Bock, Richard D., and M. Lieberman. 1970. "Fitting a Response Model for n Dichotomously Score Items." Psychometrika 35: 179-197.

Blundell, Richard W., and Richard Smith. 1986. "An Exogeneity Test for a Simultaneous Equation Tobit Model with an Application to Labor Supply." Econometrica 54: 679-685.

Brown, Peter. 2003. "Parental Education \& Child Learning: Human Capital Investments in Time and Money." Michigan University. Processed. 
Case, Anne, and Angus Deaton. 1999. "School inputs and educational outcomes in South Africa." Quarterly Journal of Economics 114(3): F1047-F84.

Coleman, James. 1966. Equality of Educational Opportunity. United States Government Printing Office: Washington, D.C.

Cox, Donald, and Emmanuel Jimemez. 1995. "Public Income Redistribution in the Philippines." In Dominique Van de Walle and Kimberly Nead, eds., Public Spending and the Poor: Theory and Evidence. Baltimore: Johns Hopkins University Press for the World Bank.

Das, Jishnu, Stefan Dercon, James Habyarimana, and Pramila. Krishnan. 2003. "Rules vs. Discretion: Public and Private Funding in Zambian Education." Development Research Group, World Bank, Washington, D.C. Processed.

Deaton, Angus, and John Muellbauer. 1980. "Economics and Consumer Behavior." Cambridge. UK: Cambridge University Press.

Dercon, Stefan, and Pramila Krishnan. 2000. "In Sickness and in Health: Risk Sharing within Households in Rural Ethiopia." Journal of Political Economy 108 (4): 688-728.

Filmer, Deon, and Lant Pritchett. 1999. "The Effect of Household Wealth on Educational Attainment: Evidence from 35 Countries." Population and Development Review 25(1): 85-120.

Foster, Andrew D. 1995. "Prices, Credit Markets and Child Growth in Low-Income Rural Areas." The Economic Journal 105(430): 551-570.

Glewwe, Paul. 2002. "Schools and Skills in Developing Countries: Education policies and socioeconomic outcomes." The Journal of Economic Literature XL: 436-482.

Glewwe, Paul, and Hanan Jacoby. 1994. "Student Achievement and Schooling Choice in Low-Income Countries: Evidence from Ghana." Journal of Human Resources 29(3): 843-864.

Greene, William H. 2001. Econometric Analysis. Upper Saddle River, N.J. : Prentice Hall.

Hanushek, Eric A. 1971. "Teacher Characteristics and Gains in Student Achievement: Estimation Using Micro Data." American Economic Review 60(2): F280-F8

Hanushek, Eric A. 1986. "The Economics of Schooling: Production and Efficiency in Public Schools." Journal of Economic Literature 24(3): F1141-F77.

Hanushek, Eric A. 1997. "Assessing the Effects of School Resources on Student Achievement: An Update." Educational Evaluation and Policy Analysis 19(2): 141-164. 
Hanushek, Eric A. 2003. "The Failure of Input-Based Schooling Policies." Economic Journal 113 (February): FF64-F98.

Holmstrom, Bengt. 1982. "Moral hazard in teams." Bell Journal of Economics 13 (2, Autumn): 324-340..

Holmstrom, Bengt, and Paul Milgrom. 1991. "Multitask principal-agent analysis: Incentive contracts, asset ownership and job design." Journal of Law, Economics and Organization 7: 24-51.

Hoxby, Caroline. 2000. "Peer Effects in the Classroom: Learning from Gender and Race Variation." Working Paper 7867. National Bureau of Economics Research. Cambridge, Massachusetts.

Jacoby, Hanan G. 2002. "Is there an Intrahousehold 'Flypaper Effect'? Evidence from a School Feeding Programme." The Economic Journal 112:196-221

Jacoby, Hanan G., and Emmanuel Skoufias. 1997. "Risk, Financial Markets, and Human Capital in a Developing Country." Review of Economic Studies 64(3, July): 311-335.

Johnson, S. R., and Gordon C. Rausser. 1971. "Effects of Misspecifications of Log-Linear Functions when Sample Values are Zero or Negative." American Journal of Agricultural Economics 53(1): $120-124$.

Kane, Thomas J., and Douglas O.,Staiger. 2001. "Improving school accountability measures." Working Paper 8156. National Bureau of Economics Research. Cambridge, Mass.

Kane, Thomas J., and Douglas O. Staiger. 2002. "The Promise and Pitfalls of Using Imprecise School Accountability Measures." Journal of Economic Perspectives 16(4): 91-114.

Krueger, Alan. 2003. "Economic Considerations and Class-Size." Economic Journal 113 (February): FF34-F63

Lazear, Edward P. 2001. "Educational production." Quarterly Journal of Economics 116(3): 777803.

Miguel, Edward, and Michael Kremer. 2003. "Worms: Identifying Impacts on Education and Health in the Presence of Treatment Externalities." Econometrica (forthcoming).

Moffit, Robert. 1992. "Incentive Effects of the U.S. Welfare System: A Review." Journal of Economic Literature 30: 1-60.

Murphy, Kevin, and Robert Topel. 1985. "Estimation and Inference in Two-Step Econometric Models." Journal of Business and Economic Statistics III: 370-379. 
Ravallion, Martin, and Gaurav Datt. 1995. "Is Targeting Through a Work Requirement Efficient? Some Evidence for Rural India." In Dominique Van de Walle and Kimberly Nead, eds., Public Spending and the Poor: Theory and Evidence. Baltimore: Johns Hopkins University Press for the World Bank..

Rosenzweig, Mark, and Kenneth Wolpin. 1994. "Parental and Public Transfers to Young Women and Their Children." American Economic Review 84: 1195-1212.

Todd, Petra E., and Kenneth Wolpin. 2003. "On the Specification and Estimation of the Production Function for Cognitive Achievement." Economic Journal 113(February): F3-33

UNESCO. Various years. "Edstats." [Retrieved on September 2, 2003, from http://devdata.worldbank.org/edstats/about_data.asp].

Urquiola, Miguel. 2003. "Identifying Class-Size Effects in Developing Countries: Evidence from Rural Schools in Bolivia." Policy Research Working Paper 2711. World Bank, Washington, D.C.

Van de Walle, Dominique, and Kimberly Nead, eds. 1995. Public Spending and the Poor: Theory and Evidence. Baltimore: Johns Hopkins University Press for the World Bank.

Wooldridge, J. M. 2001. Econometric Analysis of Cross Section and Panel Data. Cambridge. Mass.: MIT Press.

World Bank. 2001. "Zambia-Public Expenditure Review: public expenditure, growth and povertya synthesis." Report 22543. World Bank, Washington, D.C.

World Bank. Various years. World Development Indicators. Washington, D.C.

World Bank. 1998. Living Conditions Monitoring Survey II. World Bank, Washington, D.C. [free access to a segment of indicators http://www.worldbank.org/data/dataquery.html]. 
Figure 2a: Net Enrollment Rates in Africa

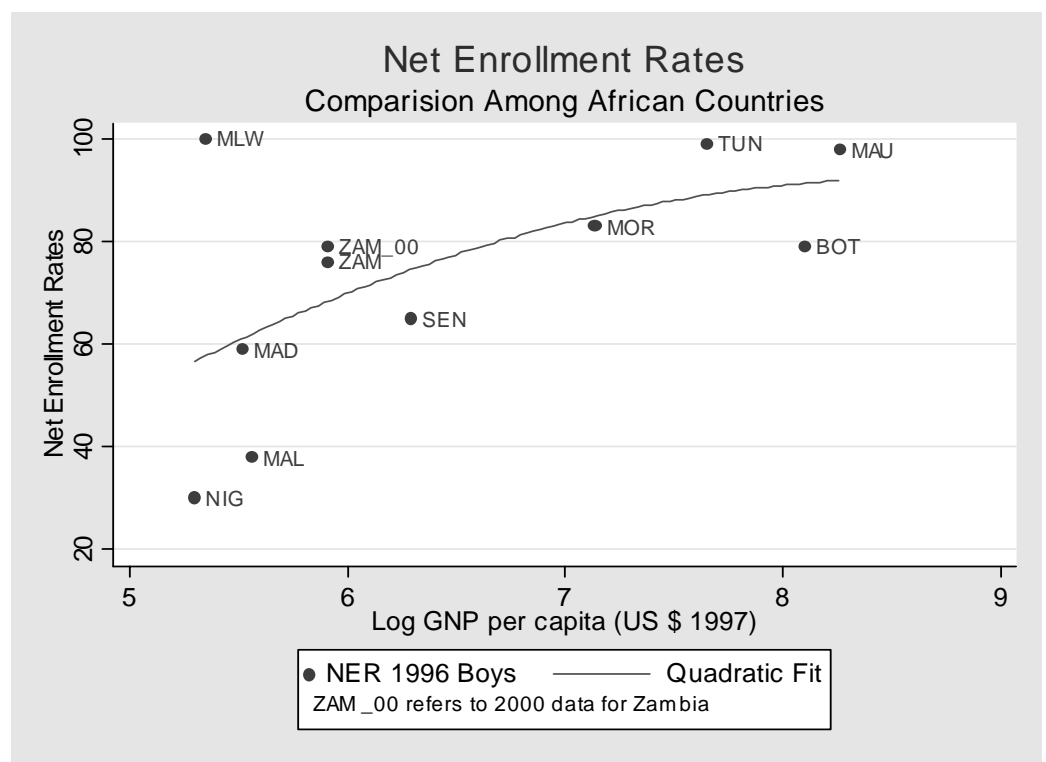

Source: UNESCO (2002). This graph shows the relationship between net enrollment rates and log GNP per capita in selected African countries, with a fitted quadratic. Zambia lies above the fitted line, suggesting that the enrollment in Zambia is greater than what would be predicted through per capita income alone.

\section{Figure 2b: Educational Attainment Curves: Zambia}
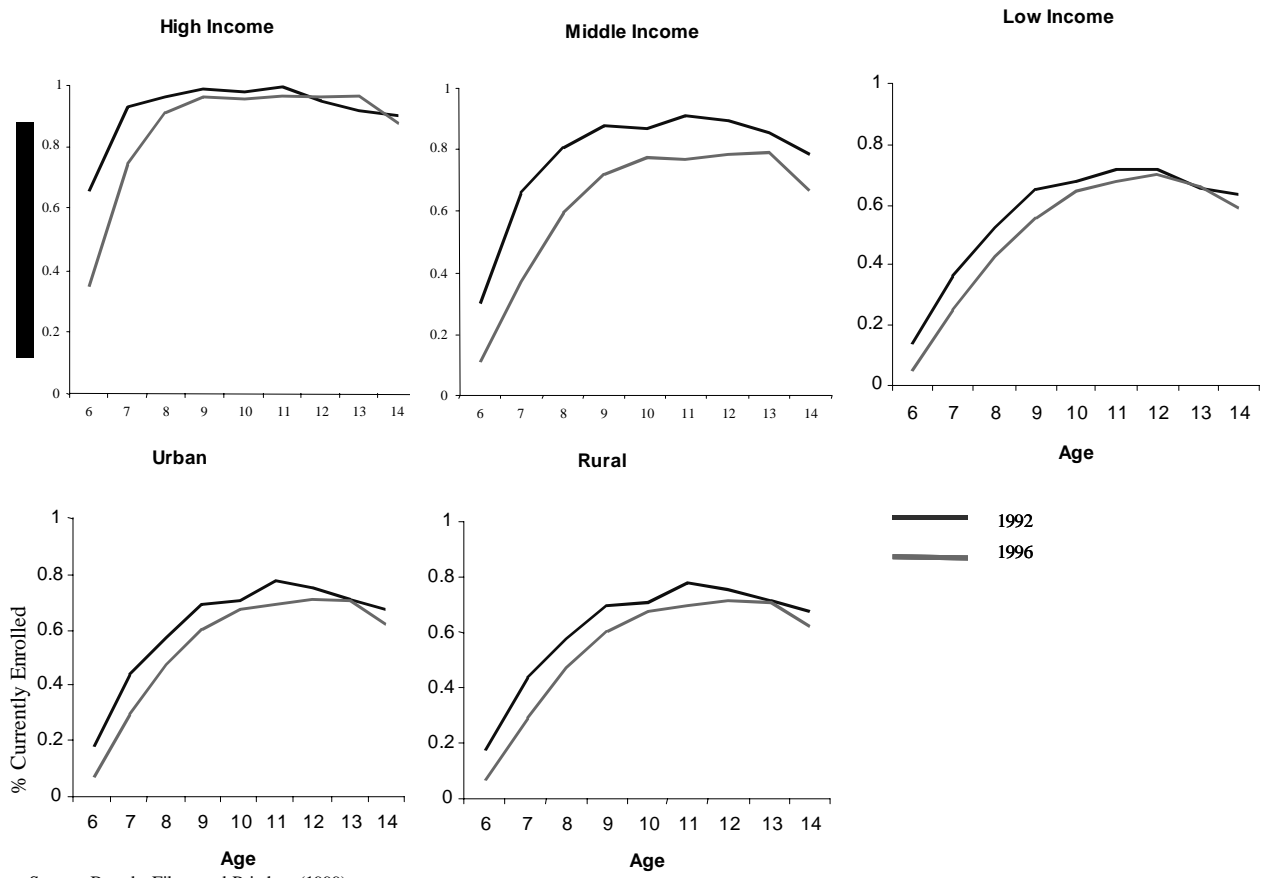

Source: Based ofrilmer and Pritchett (1999)

Note: These graphs show educational attainment plots of the percentage of children enrolled against age. For all regions and income categories, we find that strong evidence of delayed enrollment with enrollment increasing with age until age 12 and then tapering off or declining. The graphs also show how educational outcomes have worsened between 1992 and 1996, with a decline in enrollment at every age group and for all socioeconomic levels. 
Figure 3: Household Expenditures and School Funding

\section{Component Expenditure Shares House hold Sample Only}

Low Funding Schools

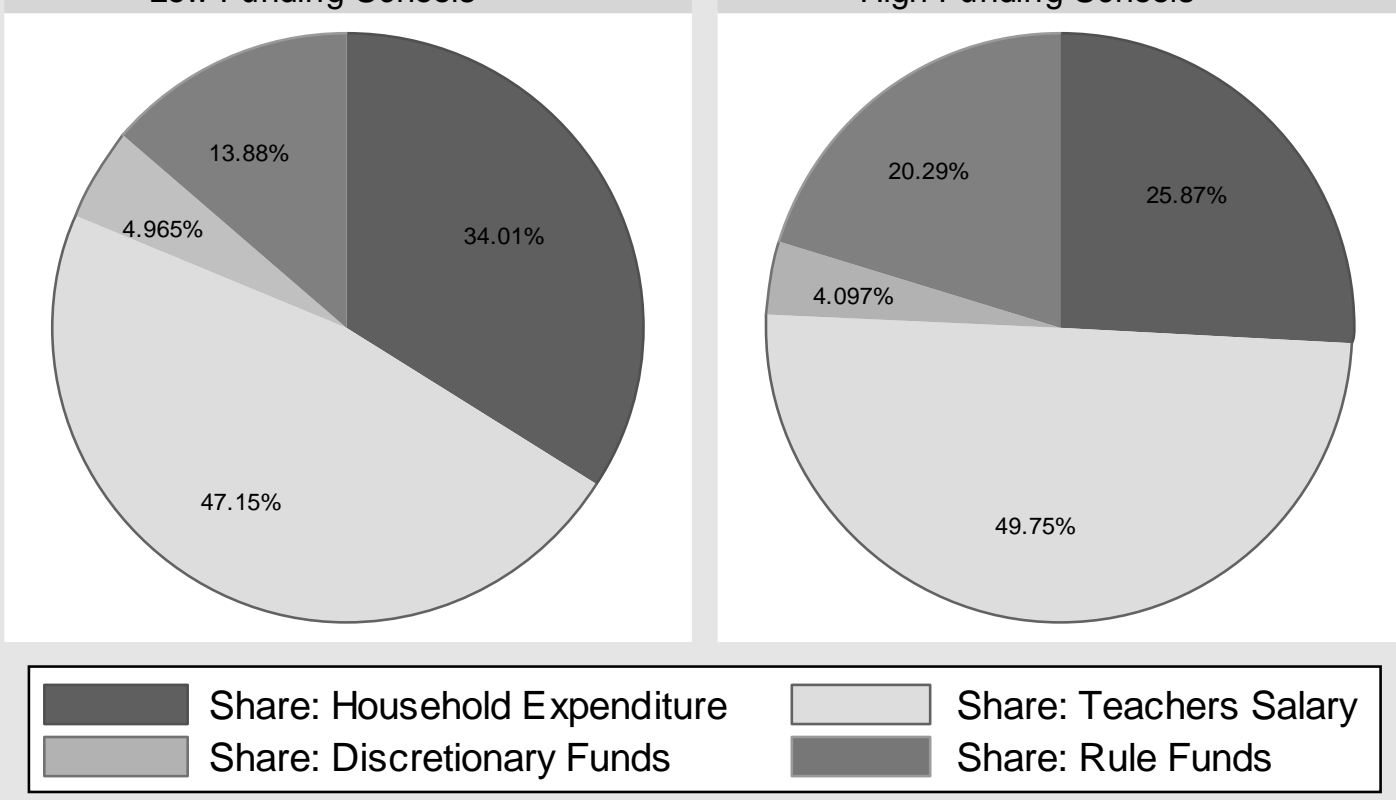

Source: ESD data

Source: ESD Sample (2002). The pi-chart shows how educational inputs are funded in schools that received high/low anticipated funds. The shares are computed as the average of shares across schools.

1. Teachers Salary is computed as salary divided by the number of students in the teachers class. This is computed for a sample of teachers who were interviewed if they were either currently teaching Grade VI or Grade V students, or had taught Grade V students in the previous year. The particular sample was chosen to ensure that teacher characteristics could be matched to students who were tested in both years. Salaries will therefore be biased if there is selection of teachers into different grade levels.

2. Household expenditure is based on a one-year recall question of household educational expenditure for every child on various items including textbooks, school supplies, and uniforms.

3. Discretionary funds are unanticipated by households. 


\section{Figure 4: Test Characteristics English and Math}

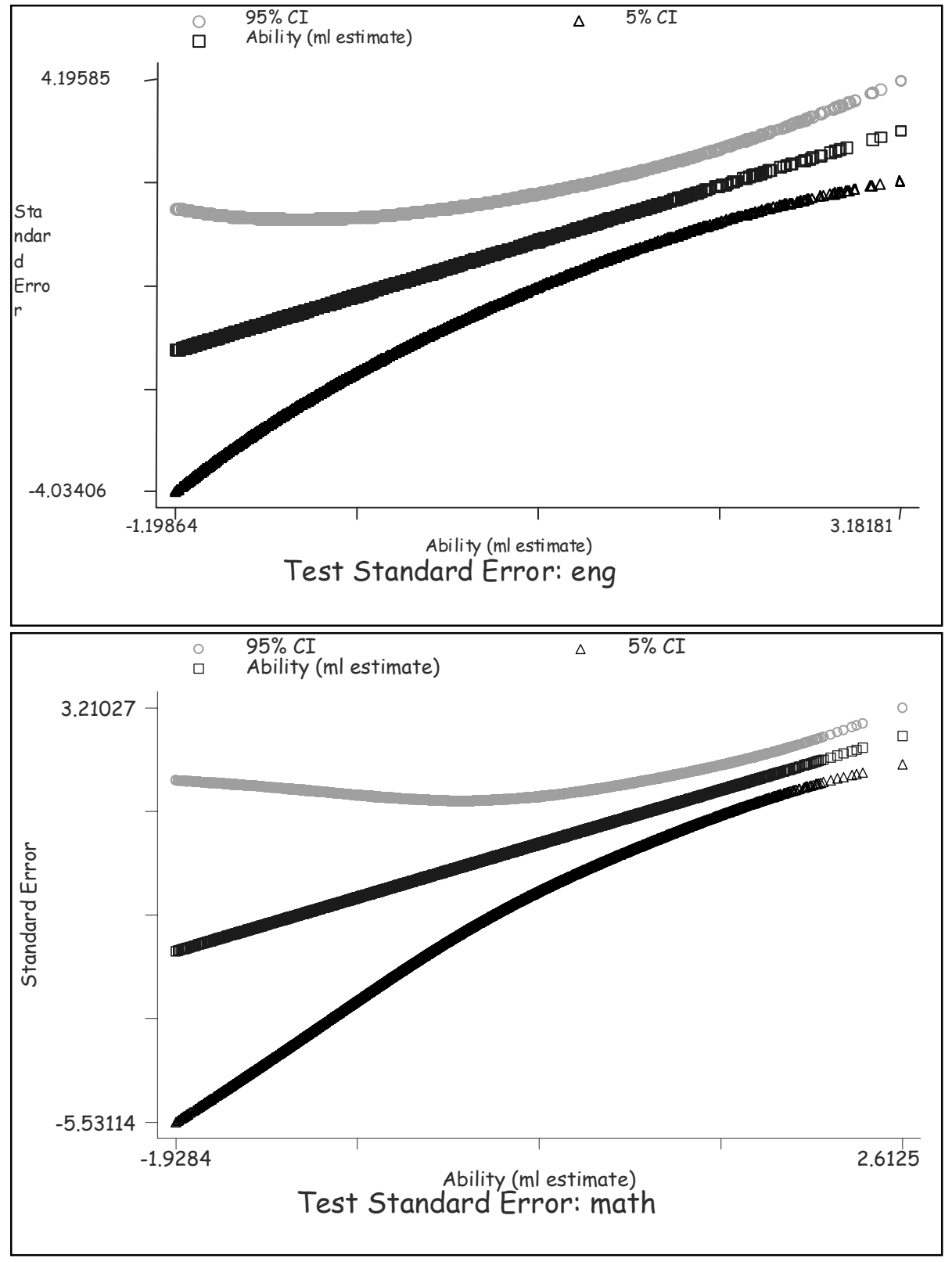

Source: Author's calculations based on Examination Council of Zambia data. These two graphs show the standard error of the estimation for the latent ability (knowledge) variable. The line in the middle plots ability against itself, while the lines on the outsides plot the 95\% confidence intervals where the standard errors are calculated from Fisher's information for maximum likelihood estimates. Thus for instance, in both the Mathematics and the English examination, the exam was "too hard" so that the confidence band at lower ability levels is larger than that at higher ability levels. Further, the Mathematics exam is more "noisy" than the English exam with larger confidence bands, especially at the lower levels. 
Figure 5: School Funding and Learning Gains

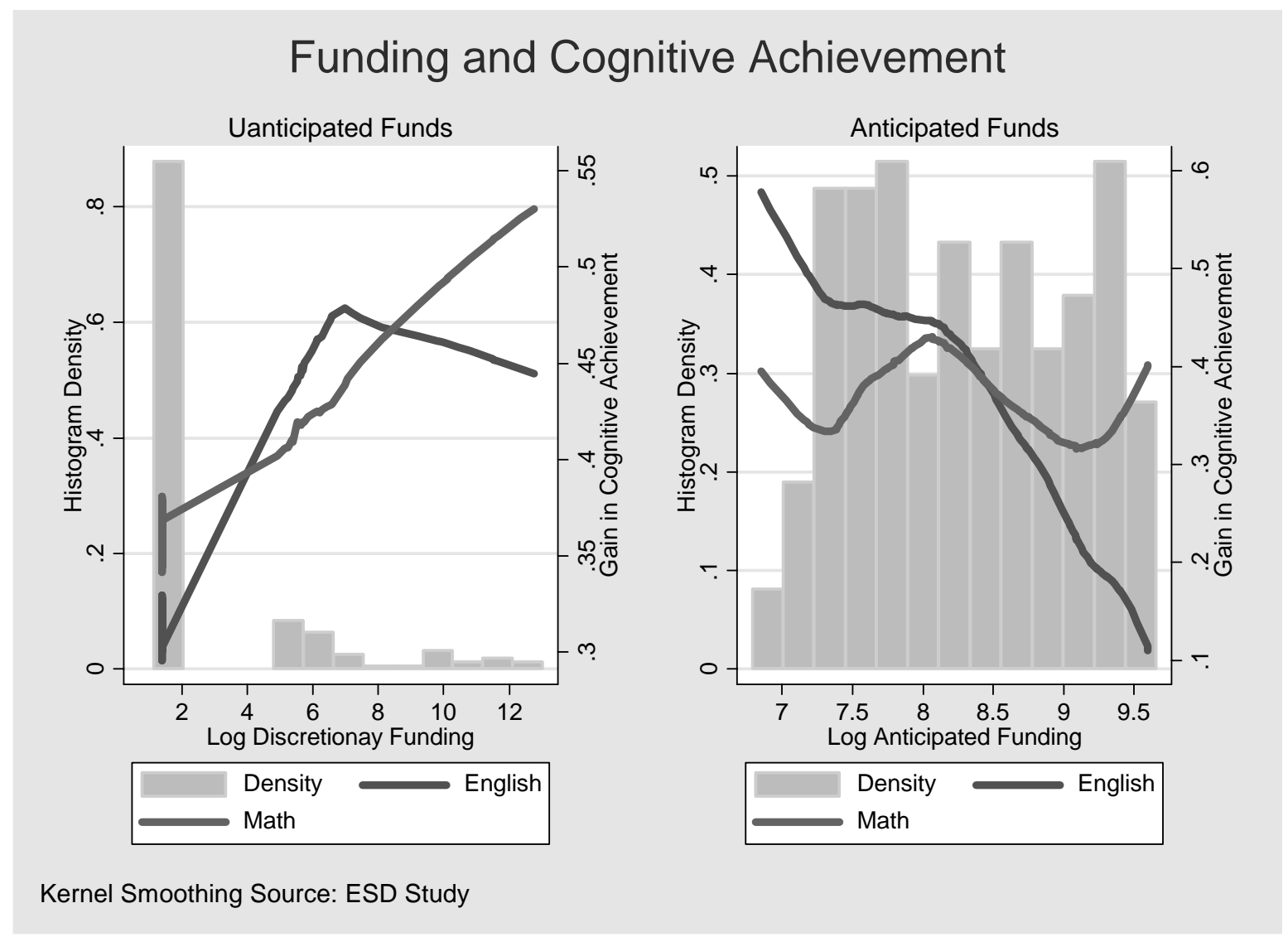

Note: This figure shows the relationship between anticipated/unanticipated funds and gains in cognitive achievement. For both graphs, the histogram of funding is plotted on the left axis and the relationship between cognitive gains and funding is plotted on the right axis. In the case of unanticipated funds, a large number of schools receive 0 funds and conditional on receipt, there is very high variance in the amount received. For anticipated funds, the distribution mirrors the distribution of enrollment and is evenly distributed on the sample range. The relationship between cognitive gains and unanticipated funding is positive and significant for both Mathematics and English and not significantly different from zero for anticipated funding. 
Table 1a: Descriptive Statistics: School Enrollment and Staffing

\begin{tabular}{|c|c|c|c|c|}
\hline Category & Variable & Urban & Rural & $\begin{array}{c}\text { 'Remote' Schools } \\
\text { (HH Sample })\end{array}$ \\
\hline \multirow{6}{*}{ Basic Indicators } & School size (number of pupils) & 1439.5 & 553.4 & 399.1 \\
\hline & & $(600.98)$ & $(408.19)$ & $(224.3)$ \\
\hline & Pupil-teacher ratio & 42.23 & 63.62 & 66.1 \\
\hline & & $(24.16)$ & $(55.14)$ & $(40.91)$ \\
\hline & Number of pupils per classroom in good & 103.4 & 96.7 & 101.4 \\
\hline & condition & $(58.41)$ & $(46.40)$ & $(59.66)$ \\
\hline \multirow{8}{*}{$\begin{array}{l}\text { Outcome } \\
\text { Indicators }\end{array}$} & Repeating the same grade $(\%)$ & 4.9 & 9.42 & 9.1 \\
\hline & & $(4.29)$ & $(6.66)$ & $(5.33)$ \\
\hline & Dropouts as ratio of current enrolment $(\%)$ & 1.67 & 4.49 & 4.6 \\
\hline & & $(2.57)$ & $(5.05)$ & $(5.28)$ \\
\hline & Pass-rate in 1999 Grade VII examination & 40.5 & 44.2 & 42.6 \\
\hline & $(\text { Males })^{1}$ & $(22.68)$ & $(27.07)$ & $(27.47)$ \\
\hline & Pass-rate in 1999 Grade VII examination & 38.6 & 40.7 & 38.4 \\
\hline & $(\text { Females })^{1}$ & $(24.32)$ & $(30.73)$ & $(30.24)$ \\
\hline \multirow{4}{*}{$\begin{array}{c}\text { Pupil } \\
\text { Characteristics }\end{array}$} & Average value of wealth-index of households & 0.57 & -0.56 & -0.73 \\
\hline & with children in the school ${ }^{2}$ & $(0.61)$ & $(.56)$ & $(0.43)$ \\
\hline & Percentage of children who are orphans & 4.7 & 4.79 & 4.9 \\
\hline & & $(3.6)$ & $(4.13)$ & $(3.5)$ \\
\hline \multirow{12}{*}{$\begin{array}{c}\text { Cash-Grant } \\
\text { Characteristics }\end{array}$} & Percentage of schools who received anticipated & 89.4 & 89.3 & 85.7 \\
\hline & funds at time of survey & $(3.7)$ & $(2.9)$ & $(5.9)$ \\
\hline & Percentage of schools who received & 23.1 & 24.8 & 14.2 \\
\hline & unanticipated funds & $(5.2)$ & $(4.0)$ & $(5.9)$ \\
\hline & Anticipated amount received (log Kwacha per & 7.66 & 8.67 & 8.93 \\
\hline & pupil) & $(0.41)$ & $(0.60)$ & $(0.54)$ \\
\hline & Unanticipated amount (log Kwacha per pupil) & 7.22 & 7.93 & 9.84 \\
\hline & & $(2.31)$ & $(2.58)$ & $(2.77)$ \\
\hline & Anticipated amount (Kwacha per pupil) & 2372.8 & 6931.4 & 8676.1 \\
\hline & & $(1535.4)$ & $(3969.7)$ & $(4852.1)$ \\
\hline & Unanticipated amounts (Kwacha per pupil) & 17121.2 & 54559.0 & 120630.9 \\
\hline & & $(36822.5)$ & $(14424.7)$ & $(158621.6)$ \\
\hline
\end{tabular}

Note: ESD Sample. Standard-Deviations in brackets.

1. Pass-Rates are for the Grade VII examination administered to all students by the Examination Council of Zambia.

2. The wealth index is based on a weighted aggregation of household assets similar to a principal components analysis, but with weights optimally derived to minimize classification errors. Details are in Das and others (2003, Appendix 1).

3. For anticipated funding, $2.25 \%$ of schools received more than the allotted amount, to a maximum of $\$ 800$. Unconditional $\operatorname{logs}$ for cash-grants are calculated by generating $\ln X=\ln (X+b)$ if $X=0$, where $b$ is determined optimally. 
Table 1b: Who Received Discretionary Funds?

\begin{tabular}{|c|c|c|c|c|}
\hline \multirow[b]{2}{*}{ Category } & \multirow[b]{2}{*}{ Variable } & \multicolumn{3}{|c|}{ Received } \\
\hline & & $\begin{array}{c}\text { No discretionary } \\
\text { funds received }\end{array}$ & $\begin{array}{l}\text { discretionary } \\
\text { funds }\end{array}$ & $\begin{array}{l}\text { Significant } \\
\text { difference? }\end{array}$ \\
\hline \multirow{8}{*}{$\begin{array}{c}\text { School } \\
\text { characteristics }\end{array}$} & School Asset Index & -0.03 & .09 & $\mathrm{NO}$ \\
\hline & & $(0.79)$ & $(.77)$ & \\
\hline & Total Enrollment in School & 862 & 981 & NO \\
\hline & & & & \\
\hline & Distance to District Office (\% & $48.1 \%$ & $60.4 \%$ & NO \\
\hline & within $5 \mathrm{KM}$ ) & & & \\
\hline & Distance to Provincial Office (\% & $20.7 \%$ & $18.6 \%$ & NO \\
\hline & within $5 \mathrm{KM}$ ) & & & \\
\hline \multirow{4}{*}{$\begin{array}{l}\text { Performance in } \\
\qquad 2001 \\
\text { examinations }\end{array}$} & English Scores in 2001 & -0.045 & -0.05 & NO \\
\hline & & $(.48)$ & $(.52)$ & \\
\hline & Mathematics Scores in 2001 & -0.012 & -.069 & NO \\
\hline & & $(0.47)$ & $(0.42)$ & \\
\hline
\end{tabular}

Source: ESD Sample. Standard-deviations in brackets. This table checks to see whether schools that received discretionary funds were "different" along observable dimensions from those that did not. We find no difference in either school characteristics or test-scores in 2001 between schools that received such funds versus those that did not. The wealth index is based on a weighted aggregation of household assets similar to a principal components analysis, but with weights optimally derived to minimize classification errors. Details are in Das and others (2003, Appendix 1). Test scores are the maximum likelihood estimates of the latent variable as described in Appendix 1. 
Table 2: Cash-Grants and School Characteristics in High and Low Anticipated Grant Villages

\begin{tabular}{|c|c|c|c|c|}
\hline Categories & Variable & $\begin{array}{c}\text { Low grant } \\
\text { schools }\end{array}$ & $\begin{array}{l}\text { High grant } \\
\text { schools }\end{array}$ & Significant? \\
\hline $\begin{array}{l}\text { Matching } \\
\text { Success }\end{array}$ & $\begin{array}{l}\text { \% School going Children } \\
\text { attending surveyed } \\
\text { school }\end{array}$ & $94.6 \%$ & $98.5 \%$ & YES \\
\hline $\begin{array}{l}\text { Outcome } \\
\text { Variable }\end{array}$ & $\begin{array}{l}\text { Average Per-Child } \\
\text { Expenditure }\end{array}$ & 19,576 & 10,794 & YES \\
\hline \multirow{4}{*}{$\begin{array}{l}\text { Explanatory } \\
\text { Variable } \\
\text { (Anticipated } \\
\text { Grants= } \\
\text { K/enrollment) }\end{array}$} & $\begin{array}{l}\text { Average Anticipated } \\
\text { Grant }\end{array}$ & 4,648 & 10,999 & YES \\
\hline & $\begin{array}{l}\text { Total Enrollment in } \\
\text { School }\end{array}$ & 572.15 & 232.77 & YES \\
\hline & Schools Asset Index & -.75 & -.93 & YES \\
\hline & Households Asset index & 0.018 & -0.054 & NO \\
\hline \multirow{5}{*}{$\begin{array}{c}\text { Observable } \\
\text { Components of } \\
\text { Households }\end{array}$} & $\begin{array}{l}\% \text { Children with mothers } \\
\text { in household }\end{array}$ & 72.5 & 79.8 & YES \\
\hline & $\begin{array}{l}\% \text { With fathers in } \\
\text { household }\end{array}$ & 65.0 & 72.5 & YES \\
\hline & $\begin{array}{l}\% \text { whose mothers can } \\
\text { read }\end{array}$ & 87.7 & 90.1 & $\mathrm{NO}$ \\
\hline & $\%$ whose fathers can read & 72.5 & 79.8 & $\mathrm{NO}$ \\
\hline & $\begin{array}{l}\% \text { who say Head- } \\
\text { Teacher is good }\end{array}$ & 0.79 & 0.84 & NO \\
\hline \multirow{2}{*}{$\begin{array}{c}\text { Observable } \\
\text { components of } \\
\text { schools }\end{array}$} & $\begin{array}{l}\% \text { who say that Teacher } \\
\text { visited household }\end{array}$ & 52.9 & 74.2 & YES \\
\hline & $\begin{array}{l}\% \text { For whom school is } \\
\text { within } 30 \text { minutes }\end{array}$ & 50.6 & 70.7 & YES \\
\hline $\begin{array}{l}\text { Village } \\
\text { Enrollment }\end{array}$ & $\%$ Enrollment in Village & .78 & .80 & $\mathrm{NO}$ \\
\hline
\end{tabular}

Note:

1. Two private schools are excluded from the sample.

2. All tests of percentages are probability tests, all tests of continuous variables are t-tests.

3. Significant differences are at the $1 \%$ confidence level.

4. Schools Asset index is the average value of the asset index for children in the school matched to the household.

This table compares observable characteristics of households and schools for schools that received low and high anticipated funds, respectively. We find that for a number of characterisitics, there is no diffference between the two categories. For variables where differences are significant (\% with fathers in households or distance to school) the relationship with enrollment is the opposite of what one might expect, suggesting that there is no systematic correlation between enrollment at the school level, which determines anticipated funding, and household characteristics. 
Table 3: Relationship between Household and School Funding

\begin{tabular}{|c|c|c|c|c|c|c|}
\hline & (1) & (2) & (3) & (4) & (5) & (6) \\
\hline & $\begin{array}{c}\text { Base } \\
\text { Regression: } \\
\text { Tobit }\end{array}$ & $\begin{array}{c}\text { Base } \\
\text { Regression: } \\
\text { Tobit with } \\
\text { Random } \\
\text { Effects }\end{array}$ & $\begin{array}{c}\text { Hypothesis } \\
\text { 2: Tobit } \\
\text { Specification }\end{array}$ & $\begin{array}{c}\text { Hypothesis } \\
\text { 2: Tobit } \\
\text { with } \\
\text { Random } \\
\text { Effects }\end{array}$ & $\begin{array}{c}\text { Test of } \\
\text { Weak } \\
\text { Exogeneity: } \\
\text { Tobit }\end{array}$ & $\begin{array}{c}\text { Test of Weak } \\
\text { Exogeneity: } \\
\text { Tobit with } \\
\text { random } \\
\text { effects }\end{array}$ \\
\hline $\begin{array}{l}\text { Log } \\
\text { Anticipated } \\
\text { Funds } \\
\text { (Received at } \\
\text { time of } \\
\text { survey) }\end{array}$ & $\begin{array}{l}-0.417 \\
{[0.147]^{* *}}\end{array}$ & $\begin{array}{l}-0.414 \\
{[0.180]^{*}}\end{array}$ & & & & \\
\hline $\begin{array}{l}\text { Log } \\
\text { Anticipated } \\
\text { Funds } \\
\text { (Legislated) }\end{array}$ & & & $\begin{array}{l}-0.567 \\
{[0.142]^{* *}}\end{array}$ & $\begin{array}{l}-0.572 \\
{[0.160]^{* *}}\end{array}$ & $\begin{array}{l}-0.759 \\
{[0.298]^{*}}\end{array}$ & $\begin{array}{l}-0.763 \\
{[0.332]^{*}}\end{array}$ \\
\hline $\begin{array}{l}\text { Log } \\
\text { Unanticipated } \\
\text { Funds }\end{array}$ & $\begin{array}{l}-0.177 \\
{[0.064]^{* *}}\end{array}$ & $\begin{array}{l}-0.175 \\
{[0.078]^{*}}\end{array}$ & $\begin{array}{l}-0.079 \\
{[0.058]}\end{array}$ & $\begin{array}{l}-0.079 \\
{[0.065]}\end{array}$ & $\begin{array}{l}\mathbf{- 0 . 0 7 7} \\
{[0.056]}\end{array}$ & $\begin{array}{l}\mathbf{- 0 . 0 7 7} \\
{[0.062]}\end{array}$ \\
\hline $\begin{array}{l}\text { Residual From } \\
\text { "Selection" } \\
\text { Equation }\end{array}$ & & & & & $\begin{array}{l}0.235 \\
{[0.343]}\end{array}$ & $\begin{array}{l}0.232 \\
{[0.383]}\end{array}$ \\
\hline $\begin{array}{l}\text { Gender of } \\
\text { Child }\end{array}$ & $\begin{array}{l}-0.044 \\
{[0.124]}\end{array}$ & $\begin{array}{l}-0.045 \\
{[0.124]}\end{array}$ & $\begin{array}{l}-0.049 \\
{[0.124]}\end{array}$ & $\begin{array}{l}-0.048 \\
{[0.123]}\end{array}$ & $\begin{array}{l}-0.050 \\
{[0.123]}\end{array}$ & $\begin{array}{l}-0.050 \\
{[0.123]}\end{array}$ \\
\hline Age of Child & $\begin{array}{l}0.293 \\
{[0.021]^{* *}}\end{array}$ & $\begin{array}{l}0.294 \\
{[0.021]^{* *}}\end{array}$ & $\begin{array}{l}0.293 \\
{[0.021]^{* *}}\end{array}$ & $\begin{array}{l}0.293 \\
{[0.021]^{* *}}\end{array}$ & $\begin{array}{l}0.293 \\
{[0.021]^{* *}}\end{array}$ & $\begin{array}{l}0.293 \\
{[0.021]^{* *}}\end{array}$ \\
\hline $\begin{array}{l}\text { Household } \\
\text { Wealth Index }\end{array}$ & $\begin{array}{l}0.723 \\
{[0.080]^{* *}}\end{array}$ & $\begin{array}{l}0.720 \\
{[0.080]^{* *}}\end{array}$ & $\begin{array}{l}0.726 \\
{[0.080]^{* *}}\end{array}$ & $\begin{array}{l}0.723 \\
{[0.080]^{* *}}\end{array}$ & $\begin{array}{l}0.726 \\
{[0.080]^{* *}}\end{array}$ & $\begin{array}{l}0.724 \\
{[0.080]^{* *}}\end{array}$ \\
\hline $\begin{array}{l}\text { Mean Village } \\
\text { Wealth }\end{array}$ & $\begin{array}{l}-0.015 \\
{[0.204]}\end{array}$ & $\begin{array}{l}-0.028 \\
{[0.242]}\end{array}$ & $\begin{array}{l}0.007 \\
{[0.203]}\end{array}$ & $\begin{array}{l}-0.003 \\
{[0.225]}\end{array}$ & $\begin{array}{l}-0.015 \\
{[0.188]}\end{array}$ & $\begin{array}{l}-0.021 \\
{[0.206]}\end{array}$ \\
\hline Constant & $\begin{array}{l}9.693 \\
{[1.589]^{* *}}\end{array}$ & $\begin{array}{l}9.673 \\
{[1.940]^{* *}}\end{array}$ & $\begin{array}{l}10.214 \\
{[1.320]^{* *}}\end{array}$ & $\begin{array}{l}10.264 \\
{[1.486]^{* *}}\end{array}$ & $\begin{array}{l}11.834 \\
{[2.722]^{* *}}\end{array}$ & $\begin{array}{l}11.860 \\
{[3.034]^{* *}}\end{array}$ \\
\hline Observations & 1410 & 1410 & 1410 & 1410 & 1410 & 1410 \\
\hline
\end{tabular}

Note: The regressions in this table show the effect of anticipated and unanticipated funding on children's educational expenditures (the dependant variable in all regressions). Estimates marked ** are significant at $1 \%$, * denotes significance at 5\% and standard errors are presented in [brackets]. Anticipated funding is either funding that had been received by the school at the time of the survey or funding that had not yet arrived. Estimates from the former are presented in columns (1) and (2) and the latter in columns (3) and (4). Columns (5) and (6) present the test of weak exogeneity (Blundell and Smith (1986)) where the residual from the first stage regression determining log anticipated funds is included as an additional regressor. All regressions control for the mean wealth of students in the school, province dummies and a rural dummy. The censoring is at 0 for the Tobit and the random effects Tobit specifications account for the clustering of errors at the level of the village. Marginal effects (conditional on being uncensored) and the probability of censoring are presented in Table 4. Further (a) for all regressions, K100 is added to zero values of discretionary funding to allow logs. The minimum funding is K900 conditional on receipt; (b) two private schools are excluded from the analysis; (c) K50 is added to enrolled children with zero educational expenditures who form $4.96 \%$ of the sample; (d) the wealth index is based on optimal maximum likelihood weights (see Das and others (2003) for details). Results are robust to alternative indices (for instance an unweighted raw sum). 
Table 4: Marginal Effects and Probability of Censoring

\begin{tabular}{|c|c|c|c|c|c|c|c|c|}
\hline & \multicolumn{2}{|c|}{ (1) } & \multicolumn{2}{|r|}{ (2) } & \multicolumn{2}{|r|}{ (3) } & \multicolumn{2}{|r|}{ (4) } \\
\hline & $\begin{array}{r}\text { Base Reg } \\
\text { Spe }\end{array}$ & $\begin{array}{l}\text { ession: Tobit } \\
\text { ification }\end{array}$ & $\begin{array}{r}\text { Base Reg } \\
\text { with Ra }\end{array}$ & $\begin{array}{l}\text { ession: Tobit } \\
\text { dom Effects }\end{array}$ & $\begin{array}{r}\text { Hypoth } \\
\text { Spe }\end{array}$ & $\begin{array}{l}\text { sis 2: Tobit } \\
\text { ification }\end{array}$ & $\begin{array}{r}\text { Hypothes } \\
\text { Rand } \\
\end{array}$ & $\begin{array}{l}\text { 2: Tobit with } \\
m \text { Effects }\end{array}$ \\
\hline & $\begin{array}{c}\text { Marginal } \\
\text { Effect at } \\
\text { Mean } \\
\end{array}$ & $\begin{array}{c}\text { Prob. } \\
\text { (Uncensored) }\end{array}$ & $\begin{array}{c}\text { Marginal } \\
\text { Effect at } \\
\text { Mean } \\
\end{array}$ & $\begin{array}{c}\text { Prob. } \\
\text { (Uncensored) }\end{array}$ & $\begin{array}{c}\text { Marginal } \\
\text { Effect at } \\
\text { Mean } \\
\end{array}$ & $\begin{array}{c}\text { Prob. } \\
\text { (Uncensored) }\end{array}$ & $\begin{array}{c}\text { Marginal } \\
\text { Effect at } \\
\text { Mean } \\
\end{array}$ & $\begin{array}{c}\text { Prob. } \\
\text { (Uncensored) }\end{array}$ \\
\hline $\log$ & -0.34 & -0.02 & -0.37 & -0.02 & & & & \\
\hline $\begin{array}{l}\text { Received } \\
\text { (rule-based) } \\
\text { Funding }\end{array}$ & {$[0.119]^{* *}$} & {$[0.006]^{* *}$} & {$[0.164]^{*}$} & {$[.012]^{*}$} & & & & \\
\hline $\begin{array}{l}\text { Log } \\
\text { Anticipated } \\
\text { Funding }\end{array}$ & & & & & $\begin{array}{l}-0.46 \\
{[0.11]^{* *}}\end{array}$ & $\begin{array}{l}-0.024 \\
{[0.006]^{* *}}\end{array}$ & $\begin{array}{l}-0.52 \\
{[0.146]^{* *}}\end{array}$ & $\begin{array}{l}-0.038 \\
{[0.010]^{* *}}\end{array}$ \\
\hline $\begin{array}{l}\text { Log } \\
\text { Discretionary } \\
\text { Funding }\end{array}$ & $\begin{array}{l}-0.15 \\
{[0.052]^{* *}}\end{array}$ & $\begin{array}{l}-0.007 \\
{[0.002]^{* *}}\end{array}$ & $\begin{array}{l}-0.16 \\
{[0.071]^{*}}\end{array}$ & $\begin{array}{l}-0.011 \\
{[0.005]^{*}}\end{array}$ & $\begin{array}{l}-0.06 \\
{[.047]}\end{array}$ & $\begin{array}{l}-0.003 \\
{[0.002]}\end{array}$ & $\begin{array}{l}-0.07 \\
{[0.059]}\end{array}$ & $\begin{array}{l}-0.005 \\
{[0.004]}\end{array}$ \\
\hline
\end{tabular}

Note: This table shows the marginal effects at mean values of the regressors based on the coefficients from Table 3. In all cases, the significance of estimated coefficients is robust to clustering at the village level. The estimated elasticity increases substantially when we use anticipated instead of received funding, confirming that households make their educational expenditure decisions before such funding is actually received. 
Table 5: Funding and Test Scores

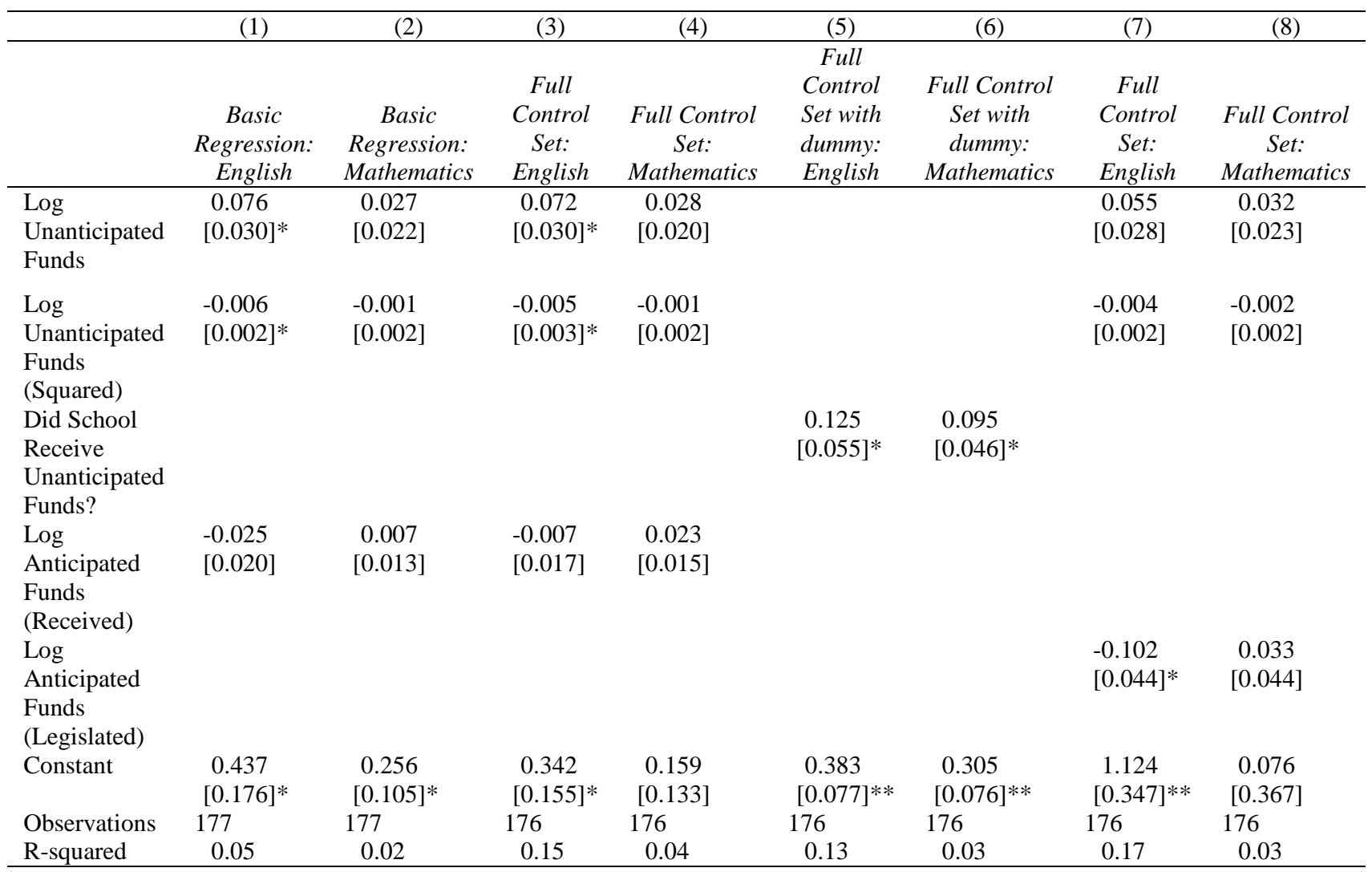

Note: This table shows OLS estimates for the relationship between unanticipated/anticipated funding and gains in cognitive achievement for English and Mathematics. For all regressions standard errors are in [brackets], * denotes significance at 5\% and ** at 10\% levels of significance. Columns (1) and (2) report coefficients without any further controls, Columns (3) and (4) include whether the school is rural, whether the head-teacher changed in the previous year, whether the PTA changed in the previous year, differences in PTA fees between 2002 and 2001 and a dummy for private schools. Columns (5) and (6) report results from using a dummy for whether the school received unanticipated funds or not with the same set of controls. Columns (7) and (8) present estimation results when we use the legislated anticipated funds rather than the anticipated funds received at the time of the survey. For the sample, 3 schools with unlikely changes ( $>2$ or $<-2$ standard deviations) are dropped from sample and the optimal $b=3.73$ is added on to unanticipated funds to compute the log. All regressions are clustered at the district level. The results from the Wald test for equality of marginal impacts for anticipated and unanticipated funds at different points of the sample range are presented in the text. The results show that we can reject the null hypothesis for English at the 5\% level for the sample mean, median, $25^{\text {th }}$ and $75^{\text {th }}$ percentile. We cannot reject the null at these values of the sample for Mathematics. 
Table 6: Predicting Discretionary Funds (First Stage)

\begin{tabular}{|c|c|c|c|}
\hline & (1) & $(2)$ & (3) \\
\hline & $\begin{array}{c}\text { Amount of unanticipated } \\
\text { funds received conditional } \\
\text { on receipt }\end{array}$ & $\begin{array}{l}\text { Amount of unanticipated } \\
\text { funds (squared) received } \\
\text { conditional on receipt }\end{array}$ & $\begin{array}{l}\text { Probability of receiving } \\
\text { unanticipated funds } \\
\text { (Marginal Coefficients) }\end{array}$ \\
\hline \multirow{2}{*}{$\begin{array}{l}\text { Grade VII Male Pass Rate } \\
\text { (2 year lag) }\end{array}$} & -0.021 & -0.366 & 0.005 \\
\hline & {$[0.018]$} & [0.306] & {$[0.007]^{* *}$} \\
\hline \multirow{2}{*}{$\begin{array}{l}\text { Grade VII Female Pass } \\
\text { Rate (2 year lag) }\end{array}$} & 0.002 & 0.010 & -0.004 \\
\hline & [0.018] & [0.307] & {$[0.007]^{*}$} \\
\hline \multirow{2}{*}{$\begin{array}{l}\text { Average school wealth (1 } \\
\text { year lag) }\end{array}$} & 0.006 & -0.196 & 0.111 \\
\hline & {$[0.628]$} & [10.741] & {$[0.203]^{*}$} \\
\hline \multirow[t]{2}{*}{ Is this a PAGE school? } & -1.643 & -28.332 & 0.229 \\
\hline & [0.859] & [14.697] & {$[0.265]^{* *}$} \\
\hline \multirow{2}{*}{$\begin{array}{l}\text { Log of district receipts } \\
\text { from external donors } \\
\text { (current) }\end{array}$} & 1.010 & 15.740 & $0 . .086$ \\
\hline & {$[0.467]^{*}$} & [7.991] & [0.166] \\
\hline \multirow{2}{*}{$\begin{array}{l}\text { Log of province receipts } \\
\text { from external donors } \\
\text { (current) }\end{array}$} & 0.148 & 2.677 & 0.037 \\
\hline & [0.497] & [8.505] & [0.175] \\
\hline \multirow[t]{2}{*}{ Contested district (first) } & 4.554 & 89.129 & -0.137 \\
\hline & {$[1.819]^{*}$} & {$[31.137]^{* *}$} & {$[0.595]$} \\
\hline \multirow[t]{2}{*}{ Contested district (second) } & 1.895 & 42.538 & 0.034 \\
\hline & [1.564] & {$[26.771]$} & {$[0.798]$} \\
\hline \multirow[t]{2}{*}{ Constant } & 1.447 & -31.409 & -0.842 \\
\hline & [4.675] & [80.014] & {$[1.622]^{* *}$} \\
\hline Observations & 38 & 38 & 164 \\
\hline R-squared & 0.50 & 0.52 & $\mathrm{LR}(\operatorname{chi} 2)=28.87$ \\
\hline
\end{tabular}

Note: This regression shows the first stage of the IV strategy using a hurdle model. For all regressions standard errors are in [brackets], * denotes significance at 5\% and ** at $10 \%$ levels of significance. Columns (1) and (2) show the estimation results conditional on receipts for unanticipated funding and unanticipated funding squared, while Column (3) estimates the probability of receiving such funding. The $\log$ of district receipts from external sources was computed through a questionnaire administered to district authorities and that for provincial receipts through surveys administered at the province level. The two dummies for politically active districts is based on interviews and newspaper articles in the run-up to the election. The predicted value for the second stage is calculated as $\mathrm{E}(\mathrm{y})=\mathrm{E}(\mathrm{y} \mid \mathrm{receipt}) \times$ Prob(receipt). 
Table 7: Learning and Funding (IV Results)

\begin{tabular}{|c|c|c|c|c|c|c|}
\hline & (1) & (2) & (3) & (4) & (5) & (6) \\
\hline & $\begin{array}{c}\text { Hurdle IV: } \\
\text { English }\end{array}$ & $\begin{array}{c}\text { Hurdle } \\
\text { IV: Math }\end{array}$ & $\begin{array}{l}\text { Hurdle IV: } \\
\text { Expected } \\
\text { Rule Funds } \\
\text { (English) }\end{array}$ & $\begin{array}{l}\text { Hurdle IV: } \\
\text { Expected } \\
\text { Rule Funds } \\
\text { (Math) }\end{array}$ & $\begin{array}{c}\text { Comparison: } \\
\text { (OLS, } \\
\text { English) }\end{array}$ & $\begin{array}{c}\text { Comparison } \\
\text { (OLS, } \\
\text { Math) }\end{array}$ \\
\hline $\begin{array}{l}\text { Hurdle } \\
\text { instrumented log } \\
\text { unanticipated } \\
\text { grants }\end{array}$ & $\begin{array}{c}0.158 \\
{[0.057]^{*}}\end{array}$ & $\begin{array}{c}0.090 \\
{[0.035]^{*}}\end{array}$ & $\begin{array}{c}0.128 \\
{[0.052]^{*}}\end{array}$ & $\begin{array}{c}0.101 \\
{[0.033]^{*}}\end{array}$ & $\begin{array}{c}0.082 \\
{[0.031]^{*}}\end{array}$ & $\begin{array}{c}0.039 \\
{[0.020]}\end{array}$ \\
\hline $\begin{array}{l}\text { Hurdle } \\
\text { Instrumented log } \\
\text { unanticipated } \\
\text { grants squared }\end{array}$ & $\begin{array}{l}-0.015 \\
{[0.007]^{*}}\end{array}$ & $\begin{array}{l}-0.008 \\
{[0.003]^{*}}\end{array}$ & $\begin{array}{l}-0.013 \\
{[0.006]^{*}}\end{array}$ & $\begin{array}{l}-0.009 \\
{[0.003]^{* *}}\end{array}$ & $\begin{array}{l}-0.006 \\
{[0.003]^{*}}\end{array}$ & $\begin{array}{l}-0.002 \\
{[0.002]}\end{array}$ \\
\hline $\begin{array}{l}\text { Log of } \\
\text { anticipated } \\
\text { grants }\end{array}$ & $\begin{array}{l}-0.024 \\
{[0.021]}\end{array}$ & $\begin{array}{c}0.008 \\
{[0.021]}\end{array}$ & $\begin{array}{l}-0.110 \\
{[0.045]^{*}}\end{array}$ & $\begin{array}{c}0.038 \\
{[0.047]}\end{array}$ & $\begin{array}{l}-0.012 \\
{[0.020]}\end{array}$ & $\begin{array}{c}0.024 \\
{[0.019]}\end{array}$ \\
\hline Observations & 164 & 164 & 164 & 164 & 164 & 164 \\
\hline R-squared & 0.16 & 0.03 & 0.18 & 0.04 & 0.15 & 0.05 \\
\hline
\end{tabular}

Note: This table shows second stage IV estimates for the relationship between unanticipated/anticipated funding and gains in cognitive achievement for English and Mathematics. For all estimates, standard errors are reported in [brackets], $*$ denotes significance at $5 \%$ and $* *$ at $10 \%$ levels of significance. Columns (1) and (2) report coefficients include controls for whether the school is rural, whether the head-teacher changed in the previous year, whether the PTA changed in the previous year, differences in PTA fees between 2002 and 2001 and a dummy for private schools. Columns (3) and (4) report results using legislated anticipated funds rather than the anticipated funds received at the time of the survey. Columns (5) and (6) report results for comparison with OLS results from the same sample. For the sample, 3 schools with unlikely changes ( $>2$ or <-2 standard deviations) are dropped and an additional 13 schools are dropped due to lack of data at the district level. All regressions are clustered at the district level. The results from the Wald test for equality of marginal impacts for anticipated and unanticipated funds at different points of the sample range are presented in the text. The results show that we can reject the null hypothesis for English at the $1 \%$ level for the sample mean, median, and $25^{\text {th }}$ percentile and at the $5 \%$ level for the $75^{\text {th }}$ and $90^{\text {th }}$ percentile. For Mathematics we can reject the null at the $5 \%$ level for the $25^{\text {th }}$ percentile and the $10 \%$ level for the sample mean and median. We cannot reject the null for the $75^{\text {th }}$ and $90^{\text {th }}$ percentiles . 